\title{
Seguint les traces de la transhumància Aproximació teòrica a partir dels resultats arqueozoològics de la fortalesa dels Vilars (Arbeca, Garrigues)
}

\section{Following the traces of the transhumance: a theoretical approach based on the archaeozoological findings of the Fortress of Vilars (Arbeca, Garrigues)}

L'existència d'una transhumància prehistòrica ha estat objecte d'un intens debat internacional. Aquesta discussió no és aliena a la recerca duta a terme a la plana occidental catalana, on en els últims anys han començat a desenvolupar-se projectes centrats en la mobilitat animal. Tot i ser encara una línia de recerca en un estadi força inicial, aquest article pretén oferir una revisió i posada al dia de l'estat actual de la recerca en aquesta zona. A partir dels resultats i indicadors obtinguts en els recents estudis arqueozoològics de la fortalesa ibèrica dels Vilars (Arbeca), es destacaran els elements a tenir en compte a l'hora d'afrontar l'estudi sobre la mobilitat animal en un context arqueològic. A partir de l'estudi de cas centrat en la fortalesa dels Vilars, s'aniran desgranant diferents aspectes teòrics com: la capacitat de manteniment dels ramats; les seves necessitats alimentàries; les diferents fonts documentals disponibles, i les limitacions inherents a aquesta línia la recerca.

Paraules clau: arqueozoologia, primera edat del ferro, època ibèrica, plana occidental catalana, transhumància, etnografia.
The existence of transhumance in Prehistory has been the subject of intense international debate. This discussion is not unrelated to the research carried out in the territories of inland Catalonia where several projects in recent years have focused on animal mobility. Although this subject of research is still in an early stage, this work attempts to offer an overview and update of the current state of research in this region. From the results of recent archaeological and archaeozoological analyses carried out at the Iberian Fortress of Els Vilars (Arbeca, Lleida), we describe the elements that must be considered when studying animal mobility in archaeological context. The study of this site also implied successively analysing different aspects such as herd management, the capacity to maintain livestock and food needs. The study also required an analysis of the available documentary sources and finally the limits inherent to this type of research.

Keywords: archaeozoology, First Iron Age, Iberian period, Inland Catalonia, transhumance, ethnography. 


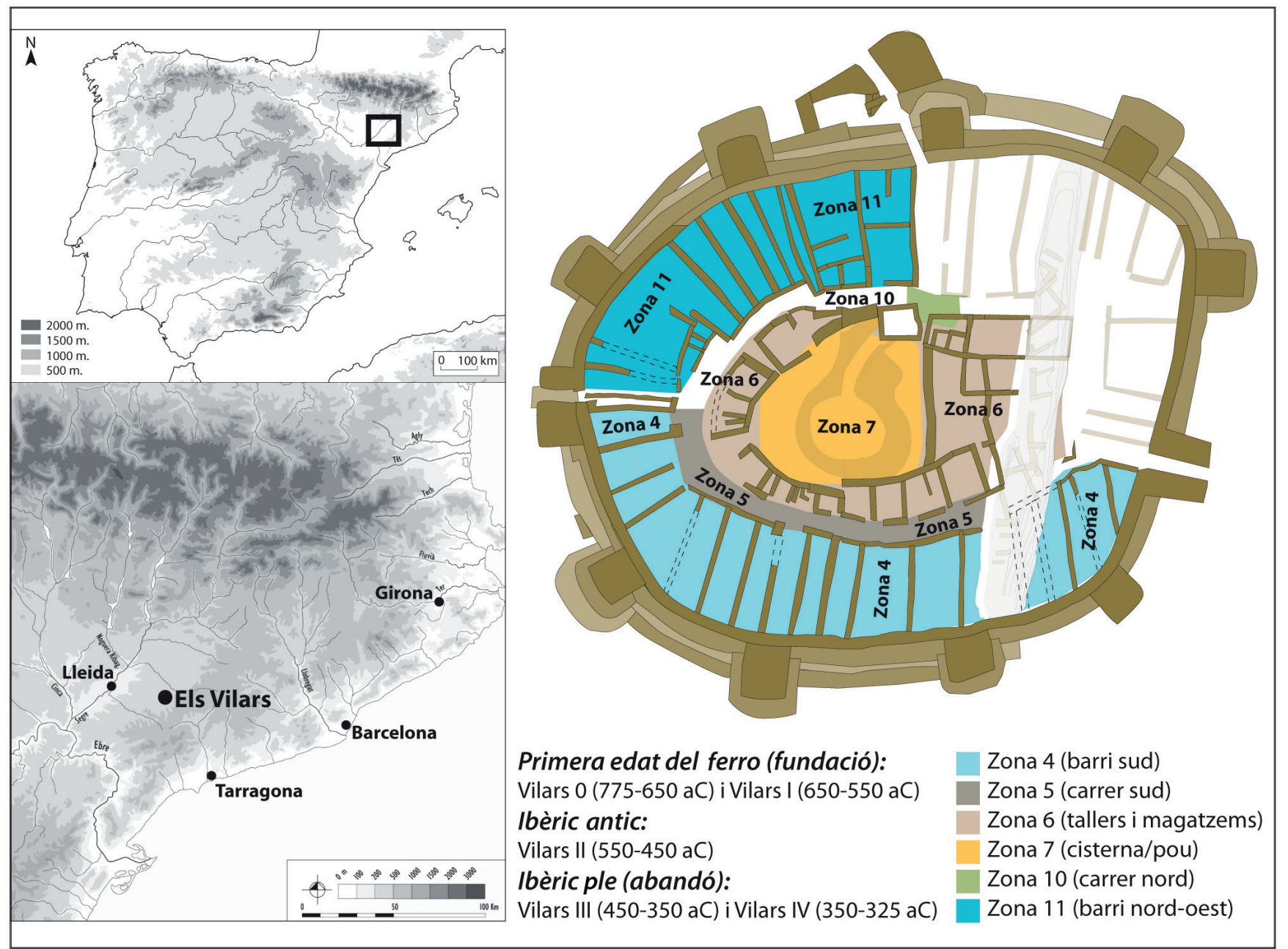

Figura 1. Localització de la fortalesa dels Vilars (Arbeca, Lleida) amb planta del jaciment i la cronologia de les diferents fases d'ocupació del jaciment.

\section{La fortalesa i els conjunts estudiats}

La fortalesa dels Vilars està situada a uns 300 metres snm, al nord-est del terme municipal d'Arbeca (Garrigues, Lleida), en una extensa plana d'acumulació al.luvial (figura 1). Les excavacions i el projecte d'investigació desenvolupats des del 1987 han deixat al descobert un $80 \%$ de la superfície del jaciment i la planta gairebé completa del recinte (figura 1), fet que ha permès definir-ne els límits i tenir-ne una visió tant diacrònica com sincrònica. El període d'ocupació és de 400 anys (del segle vIII $\mathrm{aC}$ al segle IV $\mathrm{aC}$ ) amb una seqüència estratigràfica sistematitzada en cinc fases a partir de les remodelacions urbanístiques generals i de l'anàlisi dels elements de cultura material apareguts.

El jaciment va esdevenir un autèntic tell, a partir de la superposició continuada de nivells arqueològics en un espai que no va modificar ni superar el perímetre definit per les seves muralles. Malauradament els treballs agrícoles van destruir la pràctica totalitat de les dos últimes fases, en resta tan sols un petit testimoni a la zona central del jaciment. Els seus límits estan definits per un triple cinturó defensiu constituït per una muralla de $5 \mathrm{~m}$ de gruix protegida, alhora, per dotze torres, una barrera de pedres clavades verticalment (chevaux-de-frise) i un fossat atalussat i paramentat amb murs de pedra de $13 \mathrm{~m}$ d'amplària i $4 \mathrm{~m}$ de fondària. L'interior de la fortalesa s'organitza radialment al voltant d'un espai col-lectiu o pla central presidit per una monumental bassa pou documentada amb seguretat des de mitjan segle $\mathrm{v}$ ane. És molt probable que aquesta bassa es construís sobre alguna estructura similar més antiga. La xarxa viària presenta un traçat simple estructurat en funció d'una artèria principal que discorre parallela a la muralla permetent la circulació perimetral. Els habitatges són de planta rectangular o lleugerament trapezoïdal; comparteixen murs mitgers i estan condicionats en els extrems pel traçat curvilini de la muralla i del carrer.

Els conjunts seleccionats estan compostos per restes òssies de macromamífers recuperats en diferents espais de la fortalesa. Suposen una mostra abundant de restes procedents de deixalles de consum i de conjunts tancats sota paviment. En total s'han estudiat 12.626 restes de les quals 9.683 s'han determinat (Nieto 2012). Les restes han aparegut en diversos àmbits i espais del jaciment com són: espais domèstics al barri nord (zona 11) i barri sud (zona 4); 
espais d'emmagatzematge i/o tallers (zona 6); carrers (zona 5 i zona 10), i la cisterna (zona 7). Els conjunts responien a orígens i naturaleses diverses que van permetre distingir, a grans trets, dues tipologies diferents: 1) Conjunts tancats (dipòsits sota paviment) que ja van ser tractats específicament en treballs anteriors (Nieto 2010; Nieto et al. 2010; Nieto 2013) i conjunts oberts de caràcter alimentari (deixalles de consum), que seran la base analítica sobre la qual se sustentarà aquest estudi.

\section{L'espectre faunístic de la fortalesa dels Vilars}

Els conjunts de la fase Vilars $0^{1}$ (800-775/700-675 $\mathrm{aC}$ ) presentaven una mostra faunística molt reduïda (a causa de la poca superfície excavada d'aquest moment). Situa els ovicàprids al capdamunt de la cabana domèstica, tant des del punt de vista de l'NR com de l'NMI. En segon lloc hi hauria el porc i en el tercer els lagomorfs (conill). Pel que fa a la resta de la tríada també tenim els bovins, representats per percentatges molt discrets $(4,5 \%$ en NRD i $6,8 \%$ en NMI), juntament amb els èquids que van aparèixer amb un $0,8 \%$ en NRD i un $2,3 \%$ en NMI.

Els conjunts de la fase Vilars I (700-675/550-525 aC) tenien un NR molt superior al de la fase precedent. ${ }^{2}$ la dinàmica no difereix gaire respecte de l'anterior fase. Els ovicàprids continuen essent l'espècie més representada tant a partir de l'NR com de l'NMI, i l'únic que sembla presentar una petita variació és l'augment percentual de les restes de porc. Malgrat tot, aquest tàxon segueix ocupant el segon lloc, a molta distància dels ovicàprids.

La fase Vilars II (550-525/450-425 aC) marca el primer moment de l'ibèric antic al jaciment i a banda de ser la que millor s'ha excavat, també és la que ha proporcionat un major nombre de restes. ${ }^{3}$ Les espècies representades semblen mostrar una tendència pràcticament idèntica respecte a les de les dos fases precedents. L'únic que sembla evidenciar-se (figura 2)

1. Del conjunt de la fase de Vilars 0 es van estudiar un total de 1.501 restes, de les quals $177(11,8 \%)$ eren restes de deixalles de consum i $1.324(88,2 \%)$ formaven part dels conjunts tancats sota paviment. En relació amb les restes de consum, $1.532(92 \%)$ es van poder determinar: $131(74 \%)$ a nivell anatòmic i taxonòmic, i 39 (22 \%) només a nivell anatòmic. Pel que fa a les restes indeterminades, constituïen el $6,2 \%$, amb 11 restes.

2. Del conjunt de la fase de Vilars I es van estudiar un total de 2.826 restes, de les quals $1.632(57,7 \%)$ eren restes de deixalles de consum i $1.194(42,2 \%)$ formaven part dels conjunts tancats sota paviment. En relació amb les restes de consum, $1.503(92 \%)$ es van poder determinar: $1.247(83,2 \%)$ a nivell anatòmic i taxonòmic, i $254(15,2 \%)$ només a nivell anatòmic. Pel que fa a les restes indeterminades, constituïen el $8 \%$, amb 129 restes.

3. Del conjunt de la fase de Vilars II es van estudiar un total de 6.508 restes, de les quals $5.041(77,4 \%)$ eren restes de deixalles de consum i $1.467(22,5 \%)$ formaven part dels conjunts tancats sota paviment. En relació amb les restes de consum, 4.487 es van poder determinar: $3.311(65,7 \%)$ a nivell taxonòmic i anatòmic i $1.177(23,3 \%)$ només a nivell anatòmic. Pel que fa a les restes indeterminades, constituïen l'11\%, amb 553 restes. és el progressiu però discret augment del porc i dels bovins. Tot i això, segons la unitat de quantificació, cal comentar alguns matisos ja que l'NRD mostra una disminució important del porc a partir de la fase Vilars II (ibèric antic). En canvi l'NMI mostra un augment progressiu d'aquest animal fins a la fase Vilars II i una disminució quan s'entra en la fase Vilars III (ibèric ple). Naturalment, els resultats de la fase Vilars III cal prendre'ls amb algunes reserves a causa de la limitació de la mostra i sobretot perquè hem pogut veure alguns matisos en la composició de la tríada a l'interior de les cases i al carrer. ${ }^{4}$ A partir de l'NRD es confirma l'augment progressiu dels ovicàprids i el descens de la importància del porc durant el pas de la fase Vilars I a Vilars II; és a dir, en el pas de la primera edat del ferro a l'ibèric antic. Aquest descens del suid també sembla evidenciar-se a partir dels materials de la cisterna. També hi ha un augment, tot i que discret, dels bovins ja present durant la fase Vilars II. Per la resta, i en el cas dels èquids, la tendència i els percentatges eren els mateixos respecte als treballs anteriors. L'espectre faunístic obtingut a partir de l'NMI mostra un creixement moderat d'aquesta espècie, almenys fins a la fase Vilars III. Pel que fa al porc, també va experimentar un creixement constant, però modest, fins a la fase Vilars II. En canvi, en la fase següent sembla que la cabana porcina va patir una petita davallada. La cabana bovina pràcticament mostra el mateix espectre que ja havíem vist en l'NRD, l'única diferència és un increment molt més marcat en el cas de l'NMI quan entrem en la fase Vilars III. El mateix podem dir en el cas de la cabana equina.

En resum i independentment del sistema de quantificació emprat, podem dir que la tendència que descriu el patró de consum de la cabana domèstica de la fortalesa dels Vilars mostra un progressiu augment dels bovins i ovicàprids, que contrasta amb la progressiva disminució del porc. Aquest últim tàxon experimentaria un lleuger creixement durant la fase Vilars I que es mantindria fins a la fase següent, a partir de la qual començaria un descens important de la seva representativitat. Cal advertir en aquest sentit que la fase Vilars III pateix serioses mancances pel que fa al registre, però el bon estat de conservació de les restes, tant de la cisterna com de l'espai d'hàbitat, sembla que podria estar mostrant, si més no, la tendència global del jaciment en aquest moment.

4. Cal recordar que s'ha aprofitat per quantificar conjuntament els resultats obtinguts per Miró (1992) i els nostres, ja que cronològicament corresponien a la mateixa fase i espacialment provenien de la mateixa zona del testimoni. Tot i així, en els apartats posteriors en què s'analitza l'alimentació a partir de la distribució del nombre de restes i la variació de la composició de la fauna segons la tipologia i/o funcionalitat dels espais, es tindrà en compte la separació d'aquests dos espais. 


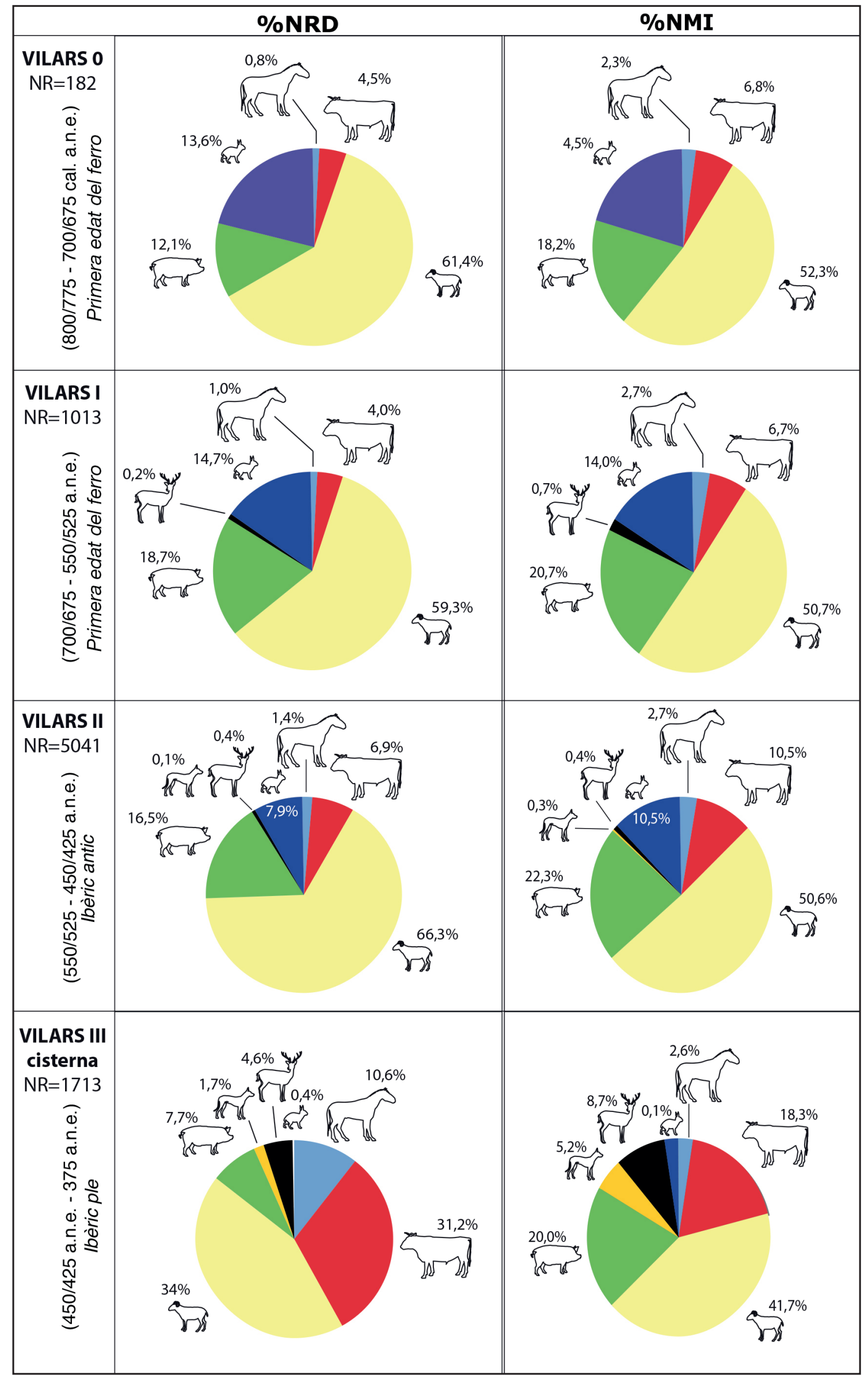

Figura 2. Espectre faunístic de la fortalesa dels Vilars per fases i en funció del NRD (nombre de restes determinades) i del NMI (nombre mínim d'individus). 


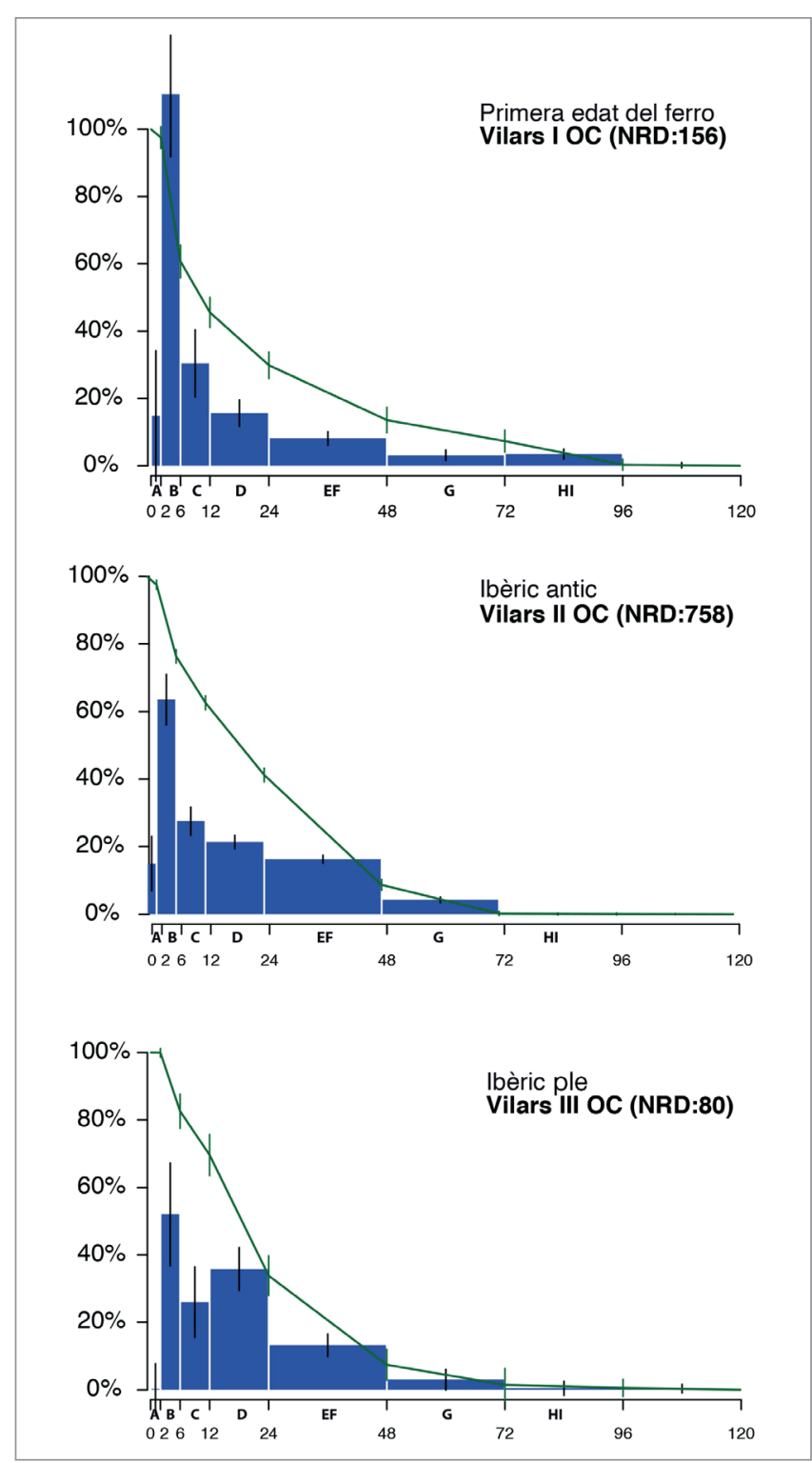

Figura 3. Corbes d'edat de mort dels caprins de la fortalesa dels Vilars per fase.

\section{La gestió dels caprins a la fortalesa}

Les corbes d'edat de mort obtingudes, evidencien que la gestió d'aquestes dues espècies (Ovis aries i Capra hircus) no sembla experimentar grans canvis al llarg de la seqüència cronològica del jaciment (figura 3), tot i que sí que sembla que hi hauria una petita variació durant el pas de la primera edat del ferro a l'època ibèrica.

Tal com mostren els historiogrames de la figura 3, tant la fase Vilars 0 com Vilars I presenten el mateix perfil. ${ }^{5}$ La gestió mostra una tendència que prioritza l'obtenció de carn, en aquest cas principalment tendra (carn tipus A, Helmer i Vigne 2004). Aquesta s'evidencia a través dels pics de sacrifici entre els 2 i 12 mesos de vida. Tot i així, el predomini de la classe B

5. Tot i que en el cas de Vilars 0 tan sols és una mera aproximació ja que els resultats se sustenten en un nombre molt baix d'efectius. mostraria que no s'està buscant només carn, que es caracteritza per una massacre centrada en les classes C i D, sinó també l'obtenció d'una part de llet. ${ }^{6} \mathrm{El}$ sacrifici dels anyells després del deslletament (classe B) permetria obtenir un millor rendiment de carn tendra i un complement no negligible de llet (Blaise 2005: 198). No obstant això, l'explotació de la llet en aquest perfil no estaria buscant un rendiment màxim, ja que majoritàriament s'haurien mantingut els petits vius en el seu període de lactància ${ }^{7}$ (0-2 mesos) aprofitant part de llet a partir de la restricció del consum dels petits (Helmer i Vigne 2004). El predomini de la classe B i C es tradueix en el sacrifici d'anyells just després del seu deslletament i una primera selecció de reproductors que sembla evidenciar, a la vegada, una primera eliminació d'excedent, de manera que abans de l'any de vida ja s'ha eliminat més de la meitat dels efectius vius del ramat. ${ }^{8}$ Aquesta predilecció pel consum dels joves, amb talls de sacrifici que suposen entre el $15 \%$ i el $36 \%$ de l'efectiu global, pot estar reflectint versemblantment un sacrifici de regulació basat en l'eliminació dels animals més joves amb la finalitat de preservar les reserves farratgeres durant l'estació d'hivern (Sidi Maamar 2000: 223), però també una certa mortalitat infantil. Fet que també sembla evidenciar-se a partir de l'alt percentatge d'avortaments que s'han pogut documentar a través de les restes de fetus (figura 7).

La fase Vilars II (període ibèric antic) mostra alguns canvis significatius en la gestió dels ramats de caprins (figura 3). D'entrada hi ha un descens important del ritme de sacrificis de la classe B (2-6 mesos) i un augment del manteniment dels animals subadults $\mathrm{i}$ adults, tal com evidencia l'augment de la classe D i EF (dels 12 als 48 mesos). Tot i que en aquest cas se segueix prioritzant l'obtenció de carn (tipus A i B), ara la gestió es diversifica i s'orienta vers un major rendiment dels recursos carnis (hi ha un major nombre d'animals que es mantenen fins a l'edat de 12 a 24 mesos). La gestió també sembla orientar-se cap a un augment de l'obtenció de llet i en definitiva de productes en vida de l'animal. Aquesta tendència a mantenir un major nombre d'individus fins als 4 anys potenciaria una major explotació de la llana i de la llet. Tot i així, en aquest moment, es constata una renovació més ràpida dels ramats, on a partir dels 4 anys només quedaria una petita selecció dels $\mathrm{i}$ les millors reproductors/es. En aquesta fase, l'única que presentava un volum important de mostra, vam poder separar els perfils oferts per les ovelles i les cabres. En aquest cas es va poder constatar que hi havia una major presència d'ovelles que de cabres (proporció de 2:1 respectivament) tal com s'evidencia

6. Aquest es caracteritza per un pic de sacrifici en els joves d'entre 0 i 2 mesos.

7. A diferència de la vaca, tant l'ovella com la cabra no necessiten la presència del petit per produir llet.

8. Cal tenir en compte que el deslletament dels animals suposa el pas de la responsabilitat de la seva alimentació de la mare a la comunitat, i poden esdevenir, doncs, una càrrega per al conjunt, que s'hauria de fer càrrec de la seva alimentació durant els mesos en què les pastures estiguessin en regressió. Això voldria dir fer ús d'una part del seu excedent agrícola per alimentar-los. 


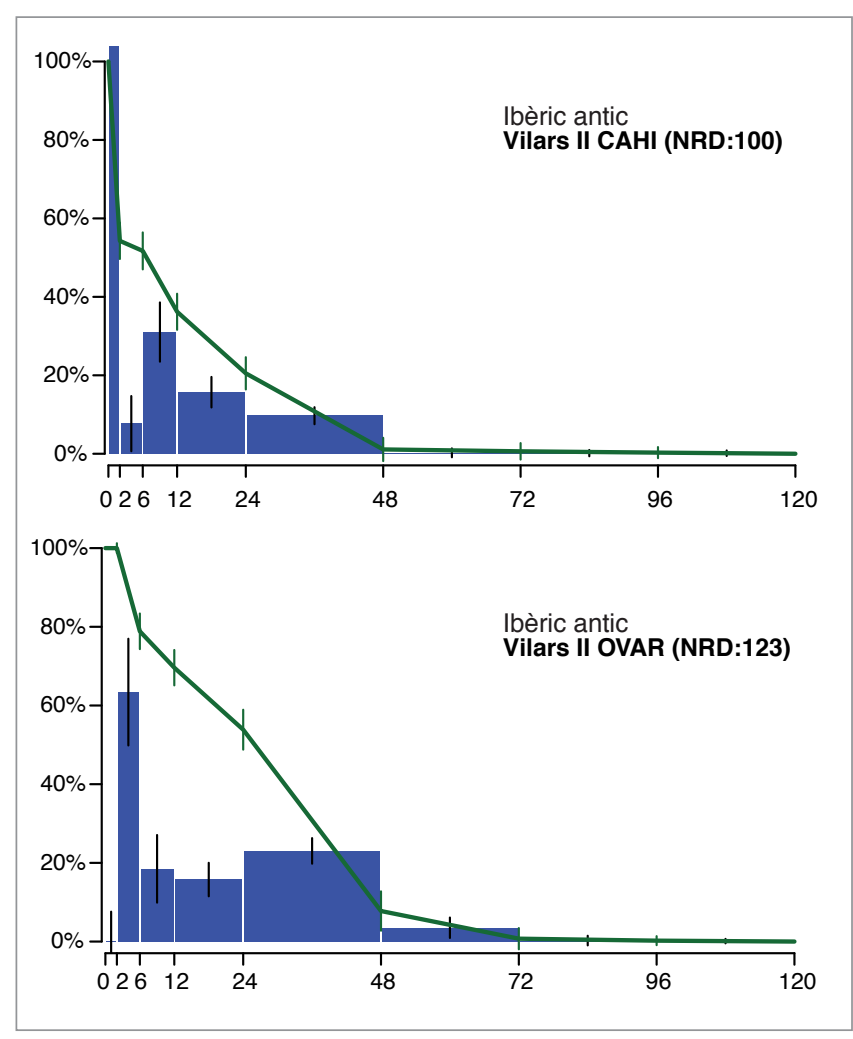

Figura 4. Corbes d'edat de mort d'ovelles i cabres per a la fase Vilars II.

en la major part dels jaciments de la prehistòria $\mathrm{i}$ protohistòria europea (Driesch 1992: 115). L'explotació d'ambdues espècies mostrava uns perfils que apuntaven un tractament diferenciat. Els perfils d'edat de mort (figura 4) apunten vers una gestió de les ovelles que situaria de manera secundària l'obtenció de llet tipus $\mathrm{B}$ (que mostra una explotació menys intensiva d'aquest producte en les ovelles respecte a les cabres), però que permetria també una explotació de la llana (també presència de classe $\mathrm{G}$ a diferència dels caprins). Tot $\mathrm{i}$ així, aquest model no afavoriria un rendiment òptim d'aquests dos productes. En definitiva, la gestió de les ovelles estaria destinada a una obtenció del màxim rendiment carni (principalment carn tendra) i de productes secundaris que pot oferir aquesta espècie, mantenint, però, una reserva genètica (classe $G$, de 4 a 6 anys) amb els millors reproductors (cosa que no s'ha pogut constatar en el cas de les cabres). En canvi, les cabres mostren una explotació intensiva de llet i una reducció del ramat de gairebé el $50 \%$ durant el primer any (mascles), seguit per un segon pic de sacrificis entre els 6 i 7 anys, que és quan la reproducció i les capacitats de producció de llet de les femelles comencen a disminuir (Stein 1987: 106). La tendència observada a Vilars mostra efectivament que durant el primer any de vida ja s'ha eliminat un $50 \%$ del ramat, sense poder assegurar si hi ha una priorització en el sacrifici dels mascles o de les femelles. Els ramats de cabres es renoven ràpidament evitant un manteniment d'animals en edat adulta. Entre els 24 i els 48 mesos es produeix el sacrifici de les femelles que produeixen menys llet i/o poc prolífiques. D'aquesta manera, tot sembla apuntar que en el moment en què la producció de llet de les femelles començava a decréixer, s'eliminava la pràctica totalitat dels efectius vius.

Aquest sistema complementari de gestió de cabres i ovelles estaria destinat a una recerca de l'equilibri i potenciació dels millors productes que pot oferir cada espècie, això sí, mantenint-ne un control estricte de la talla. Tanmateix, tot sembla apuntar, si tenim en compte que una producció de llet tipus A suposa un ritme intens de sacrifici dels animals més joves, que aquest tipus de gestió representaria un perill real per a la supervivència del ramat si aquest no comporta un nombre d'animals suficientment grans (Helmer i Vigne 2004: 406).

La fase Vilars III, tot i les reserves amb què hem de tractar aquests resultats, sembla mostrar a grans trets alguns canvis de tendència respecte a l'ibèric antic (figura 3). Tot i que aquest període també mostra una priorització per l'obtenció de carn, ara hi ha una disminució significativa del sacrifici d'animals de 2 a 6 mesos. Aquesta dinàmica contrasta amb un augment important dels sacrificis entre els $12 \mathrm{i}$ els 24 mesos (òptim carni), que ara passa a ocupar per primera vegada el segon pic de sacrificis. Tot $\mathrm{i}$ que els animals es mantenen durant més temps, els ramats se segueixen renovant ràpidament de manera que passats els 4 anys només quedaria una petita selecció dels i les millors reproductors/es.

En el cas de la fortalesa, sembla que hi ha un equilibri molt fi fomentat per una gestió més orientada cap a la seguretat, ${ }^{9}$ en comptes de l'optimització de l'obtenció d'energia i/o carn (Nieto 2012: 392-393). Amb això volem dir que sembla que hi hagi una voluntat expressa de minimitzar les fluctuacions de la talla dels ramats (Redding 1984, 235). El material dels Vilars s'ha comparat amb els patrons esperats de sacrifici de dos estratègies generalitzades de ramaderia orientada vers la subsistència: la producció de carn per al consum local i la seguretat del ramat (Nieto 2012: 394). La priorització de l'obtenció d'energia i proteïna evidenciaria un consum dels mascles en el seu pes òptim; és a dir, entre els 2 i 3 anys, donant lloc a una reducció de la talla del ramat al voltant del $50 \%$ en aquest moment. Les femelles, en canvi, es mantindrien fins que les seves capacitats reproductives comencessin a davallar, fet que es plasma en un pic de sacrificis secundari entre els 6 i 7 anys.

La tria econòmica, en el cas de la gestió dels ovicàprids, sembla haver-se especialitzat en l'obtenció de carn (sobretot la carn tendra durant les primeres fases) i un equilibri entre carn tendra i òptim càrnic a mesura que avança el període ibèric. Aquest fet queda palès quan comparem les corbes proposades per Stein (1987) amb les de Vilars I, Vilars II i Vilars III (vegeu Nieto 2012: 392-393). En aquest sentit les dades proporcionades per la fortalesa, sobretot pel que fa a la primera edat del ferro, no s'ajusten a cap dels dos patrons esperats. Aquest fet suggereix, d'entrada, que la fortalesa ni exportaria ni tampoc rebria ani-

9. "La seguretat del ramat" es defineix com la minimització de les fluctuacions en el rendiment dels animals i els seus productes, que queden per sota de les necessitats de subsistència dels pastors (Redding 1981). 
mals d'altres assentaments, almenys durant aquestes primeres fases d'ocupació. La principal presència de perfils de carn tipus A suggereix una explotació domèstica (familiar i/o comunal) d'autoabastiment, ${ }^{10}$ més que una producció orientada vers l'obtenció d'excedent per a l'intercanvi amb altres comunitats (Helmer i Vigne 2004: 405). A més a més, quan les ovelles i les cabres són criades per al consum local de carn, i no per a l'exportació, tots els grups d'edat han d'estar presents en el registre (Stein 1987: 107), cosa que s'exemplifica clarament en el cas de Vilars.

Les implicacions interpretatives d'aquesta tendència podrien explicar, d'una banda, la voluntat de fer front a la reducció de la producció anual, i de l'altra, el manteniment d'una quantitat constant dels efectius que no sobrepassi la capacitat de manteniment de la fortalesa. Sobretot durant la primera edat del ferro s'hauria dut a terme una reducció voluntària de la talla dels ramats, principalment d'ovelles, a l'entrada de l'hivern ${ }^{11}$ (tal com evidencien els pics de sacrifici de la classe B). També pot ser que estigués reflectint un alt índex de mortalitat infantil a causa de la incapacitat d'aquesta comunitat de mantenir un major nombre d'animals en els moments en què les condicions mediambientals són més dures?

\section{La fortalesa i el seu entorn}

El potencial pecuari d'un territori depèn de les formacions vegetals, de les tècniques ramaderes i de les tècniques i produccions agrícoles. Així doncs, a partir de les necessitats de cada espècie de la tríada domèstica de la fortalesa, ens vam plantejar principalment tres preguntes:

1. La fortalesa dels Vilars tenia la capacitat de mantenir els seus ramats a partir de la producció agrícola i de l'entorn natural?

2. L'àmplia presència de fetus detectada es pot considerar l'evidència d'una ramaderia poc desenvolupada i una alimentació deficient?

3. Cal plantejar-se la necessitat i existència de la transhumància durant la primera edat del ferro $\mathrm{i}$ l'època ibèrica? Quines evidències en tenim?

10. Segons Stein $(1987,107)$ en una economia de productors per a centres més grans, es destinaria els animals joves (en la seva majoria mascles amb edats entre 1 i 3 anys) a la producció de carn, mantenint al mateix temps les femelles més velles al poble com a garantia reproductiva dels ramats. Una estratègia ramadera d'aquest tipus generaria un patró complementari als centres i pobles. Els centres, com a zones de consum, presentarien un pic molt accentuat de sacrifici entre 1 i 3 anys, amb els animals menors i majors de 3 anys pràcticament $\mathrm{o}$ totalment absents del seu registre faunístic. En canvi, els ovicàprids de les zones productores mostren pics de sacrifici en animals juvenils, juntament amb un altre pic entre els 6-7 anys, quan el ramat de cria comença a perdre el seu valor. La presència d'animals entre 1 i 3 anys ha de ser rara o absent en els pobles que produeixen per a l'intercanvi.

11. El màxim pic de ritme de sacrificis està entre els 2 i 6 mesos, moment de deslletament i entrada a l'hivern. La majoria dels pics, per les ovelles, estan entre els 3 i 4 mesos coincideixen amb el període comprès entre desembre i febrer. En canvi, els caprins se sacrifiquen majoritàriament durant els mesos d'estiu (de juliol a agost), quan tenen entre 0 i 2 mesos.

\section{La fortalesa dels Vilars tenia la capacitat de mantenir els seus ramats a partir de la producció agrícola $i$ de l'entorn natural?}

En la situació de les societats antigues, la combinació entre les pastures, l'obtenció de farratges, cereals i llegums per complementar la dieta ${ }^{12}$ de les diverses espècies domèstiques en les èpoques més dures, i el control de la talla dels ramats, hauria estat la clau per dur a terme amb èxit una producció adaptada a les necessitats i possibilitats de l'època, en termes de rendiment energètic.

El tema de la quantitat d'aliment, ja sigui a través de les pastures o de l'aport de palla, farratges, cereal i lleguminoses obtingudes a partir de l'excedent agrícola, és difícil de determinar. Saber de quines produccions i quines quantitats estem parlant és molt complicat, però encara ho és més saber quina quantitat es destinava al consum animal de la fortalesa. Les principals raons d'aquests buits es poden descriure en diversos punts:

- Dificultat de reconstruir el nombre real de caps de bestiar de cada espècie a partir del conjunt d'animals morts.

- Impossibilitat de saber les hectàrees que destinaven exactament a pastures, conreu de cereals, guaret, horts, etc., en cada fase ocupacional.

- Impossibilitat de saber exactament quina producció anual tindria aquesta comunitat. Pel que fa a la plana occidental, hi ha alguns aspectes problemàtics que no tenen tant a veure amb la potencialitat natural de la zona, sinó amb la constatació d'una inestabilitat considerable de les collites i també a la manca d'estructures d'emmagatzematge importants (Alonso 1999).

- Absència de sistemes d'emmagatzematge destinats a guardar els farratges i la palla ${ }^{13}$ per a l'alimentació animal. De retruc és impossible saber quina quantitat potencial podien destinar a l'alimentació dels animals. En canvi, sí que s'han pogut documentar a la plana grans tenalles que podrien arribar a emmagatzemar fins a 70 litres de cereal. Aquestes quantitats, però, respondrien a les necessitats i autoabastiment del consum humà.

- No s'ha pogut documentar materialment la presència de l'arada dental ni de la rella de ferro (Alonso 1997: 298). Tampoc no s'ha pogut constatar l'ús del carro perquè no s'han localitzat restes directes

12. En els mesos de recessió de les pastures Columel.la (a De re rustica) afirma que la millor alimentació que poden rebre és a través de l'ordi barrejat amb faves.

13. A partir d'algunes consultes a pagesos i agricultors de la zona (fonts orals), sobre l'emmagatzematge de la palla i els farratges del bestiar, tots parlen de l'elaboració de pallers amb fang situats a les eres, propers als llocs on s'efectuava la trilla $\mathrm{i}$ el ventat del gra. Aquestes estructures protegien la palla $\mathrm{i}$ la mantenien seca durant tot un any, passat el qual, i quan ja s'havien buidat, s'abandonaven per construir-ne de noves l'any següent. Aquesta pràctica, avui dia ja perduda a la plana occidental catalana, es continua practicant en països del nord d’Àfrica com, per exemple, a la zona de Tunísia. Naturalment aquestes estructures situades fora muralles i construildes amb materials peribles no haurien deixat rastre en el registre arqueològic. 
de rodades ni cap element que se li associï. La constatació de la seva presència és important perquè va associada a un tipus de conreu de guaret curt que requereix la presència d'animals de tir (Boserup 1967: 25) i que a la vegada garantiria una major producció que permetria destinar una part important a l'alimentació dels ramats. Tanmateix, a partir dels treballs carpològics d'Alonso, s'ha pogut inferir un tipus de conreu de cicle curt principalment centrat en els cereals d'hivern (blat nu i ordi), un tipus de sistema de conreu que va molt associat a la presència de l'arada i un major rendiment i produccions cerealístiques.

Les dades arqueofaunístiques contrastades amb les carpològiques i les antracològiques poden aportar informació sobre tots aquells aspectes vinculats a la gestió agrícola i paisatgística que duia a terme aquesta comunitat. En definitiva, les dades faunístiques poden omplir alguns d'aquests buits sobre com es complementava i es retroalimentava la gestió dels ramats. El que ens interessa és veure si el registre material ha deixat nous indicis sobre la capacitat que tenien els habitants de la fortalesa de mantenir i d'alimentar els seus animals. En primer lloc, si tenim en compte els punts enumerats anteriorment, prenem consciència que cada espècie té unes necessitats específiques, tant a nivell alimentari com d'allotjament. Tant els bovins com els caprins necessiten una alimentació de qualitat, basada principalment en les pastures de primavera. ${ }^{14}$ Les cabres són animals molt més soferts ja que poden viure alimentant-se dels erms, marges i zones de sotabosc durant pràcticament tot l'any. A més és una espècie que permet un major rendiment amb un menor cost alimentari. Les vaques, en canvi, tenen una alimentació més similar a la de les ovelles; necessiten pastures de qualitat i suposen una major inversió energètica, sobretot els destinats al treball i les mares gestants. Aquestes dues espècies prefereixen les zones de planura amb climes poc extrems. Les pastures podrien satisfer pràcticament la totalitat de les necessitats alimentàries de vaques/bous i ovelles només durant els mesos de primavera i principis d'estiu, que és el màxim moment de creixement de

14. Trobem multiplicitat d'estudis que han teoritzat sobre les necessitats bàsiques per a un nombre determinat de caps de bestiar. Per exemple, Pilar Iborra (2004) va fer un recull d'alguns d'aquests treballs entogràfics actuals. Els de Coop i Devendra (1982) plantegen una estimació de la quantitat de caps de bestiar d'ovicàprids que podria mantenir una comunitat en funció de les hectàrees que necessita cada animal per alimentar-se. Els resultats diuen que la quantitat d'ovelles que es podrien mantenir en una zona agrícola són d'1 a 4 ovelles/ ha, mentre que en un sistema totalment extensiu es podrien mantenir de 0,1 a 0,5 ovelles/ha. També inclou les referències de Castel (1996: 233, citat per Iborra 2004: 334), que afirma que els ramats mixtos en una explotació extensiva han de tenir una talla mitjana de 20 caps, en explotacions amb terres, i de 9 caps, en explotacions sense terres. L'últim autor citat és Sierra Alfancra (1996: 102), que va més enllà i planteja un cas pràctic on s'afirma que per al manteniment d'unes 500 ovelles en sistema tradicional i amb un part anual, serien necessàries 840 hectàrees repartides de la següent manera: 150 de pastures de serra, 110 de bosc, 140 de turó, 120 d'erms, 240 de cereal de secà i 80 de regadiu. Aquestes dades ens poden donar una idea del cost i l'explotació mínima necessària per al manteniment d'aquesta espècie. l'herba (de mitjan març fins al mes de juliol) (figura 5). La resta de l'any caldria complementar la seva dieta amb excedent agrícola i farratges.

Els porcs, en canvi, són una espècie més adaptable per la seva condició omnívora. Des de final d'octubre fins al febrer els boscos són especialment productius amb fruits, de manera que aquests animals disposarien d'una quantitat important d'aliments (rostoll del guaret, glans, fruits dels arbres i arbusts, invertebrats que desenterren, etc.). De novembre a febrer és quan maduren i cauen les glans ${ }^{15}$ als boscos de roure, així doncs aquests animals disposarien d'una alimentació òptima en una zona molt pròxima al jaciment. Els mesos de tardor, hivern i primavera aquests animals es podrien nodrir pràcticament de manera íntegra amb els recursos naturals procedents principalment dels boscos. En canvi, durant els mesos d'estiu l'aport d'aliments per l'home seria vital a causa de la manca d'aliments disponibles de forma natural (Hadjikoumis 2010: 314).

Un cop tingudes en compte les necessitats alimentàries de la tríada, caldrà contrastar aquestes dades amb la informació proporcionada per l'ampli ventall d'estudis interdisciplinaris sobre el paisatge i l'agricultura en el territori de la fortalesa dels Vilars. En primer lloc, les anàlisis antracològiques de les diverses fases (Ros 1992; Alonso et al. 1998) van evidenciar una lleu evolució del paisatge marcada per la progressiva alteració antròpica, almenys de la primera edat del ferro fins a l'ibèric ple. Mentre que les fases de la primera edat del ferro (Vilars $0 \mathrm{i}$ Vilars I) presenten un aspecte forestal esquitxat per taques de vegetació arbustiva, els boscos d'alzines (principalment) i roures ocuparien bona part del territori, formant masses forestals importants. També hi havia formacions vegetals de tipus més obert, amb arbusts heliòfils i escleròfils, com les estepes (Cistus), el garric (Quercus coccifera), el romaní (Rosmarinus officinalis), les lleguminoses arbustives $\mathrm{i}$ arbres poc exigents com el pi blanc (Pinus halepensis). Cal destacar que els resultats de Vilars I reflecteixen una major degradació forestal, imposada per l'ocupació reiterada de l'espai. La fase Vilars II a grans trets reflecteix un entorn similar al d'ocupacions anteriors, però amb un major registre antracològic de la vegetació de ribera. Els espais oberts colonitzats per matolls i l'estrat arbori de pi blanc protagonitzarien processos de degradació/recuperació forestal en forma de comunitats secundàries. Finalment, durant la fase Vilars III continuarien els espais forestals i les formacions de caràcter més obert, i prendrien un fort protagonisme les comunitats secundàries de substitució. En segon lloc, els treballs carpològics van evidenciar un tipus de conreus centrats principalment en l'obtenció dels cereals d'hivern (blat nu i ordi vestit), l'ús del

15. Les glans són els fruits recol-lectats més freqüents a la plana occidental, tant a l'edat de bronze com a la del ferro (Alonso 1997: 275). Cal dir que la presència de glans també s'ha documentat als diversos jaciments de la zona. Aquest fruit hauria estat recol-lectat pels pobladors dels Vilars per al consum humà, però segurament també per alimentar els porcs. 


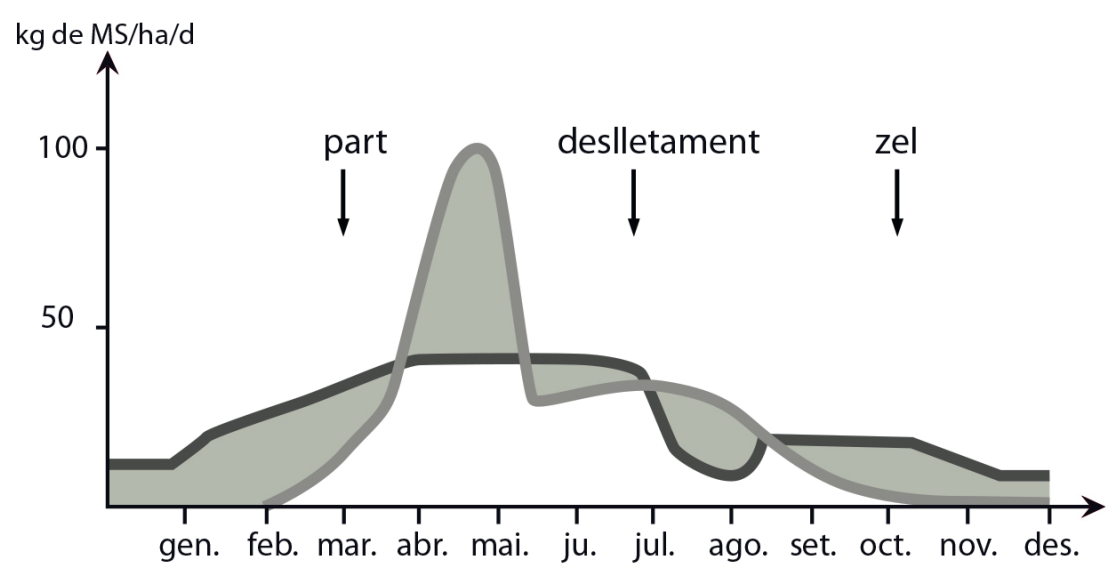

creixement de l'herba necessitats del ramat

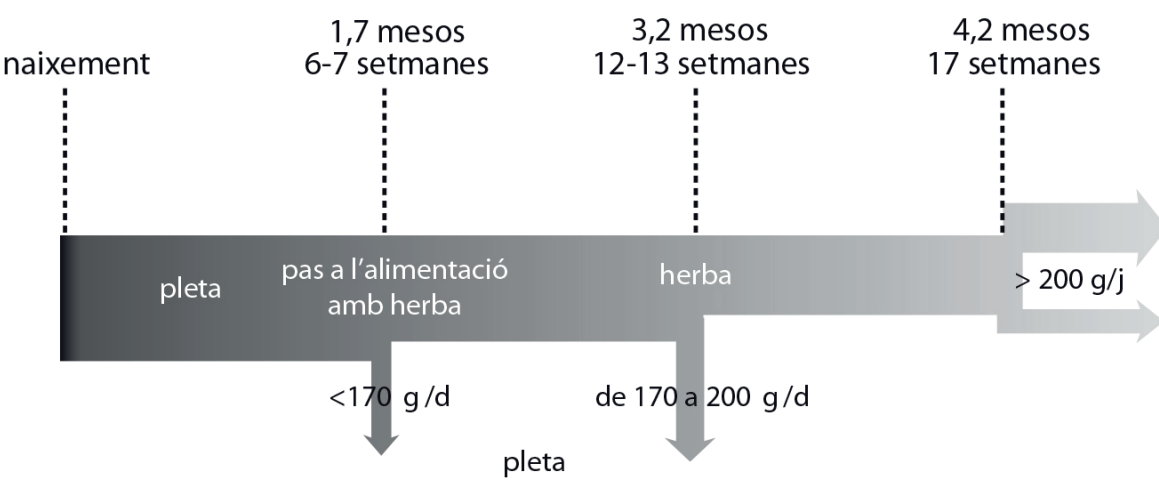

anyells per al

consum carni

anyells de

reforma

Figura 5. Figura amb les dos corbes de creixement de l'herba (pastures) i necessitats alimentàries dels corders (Drogoul et al. 2004: 272).

guaret, ${ }^{16}$ la presència de lleguminoses en un context més hortícola, la introducció de l'arada i de les eines de ferro durant l'ibèric antic. ${ }^{17}$

Per a un correcte manteniment dels ramats calia disposar d'un excedent suficient de farratges durant la primavera, que limités els efectes d'un dèficit durant l'estiu i permetés acumular unes bones reserves per a l'hivern. Els pobladors dels Vilars disposarien doncs dels següents recursos en un radi de $5 \mathrm{~km}^{18}$ (figura 6):

16. Aquest permetria establir un equilibri entre ramaderia i agricultura, ja que en els moments de descans de la terra els animals podrien pasturar i a la vegada abonar les terres. Des d'Hesíode a Xenofont, quan es parlava de les tècniques ramaderes era molt habitual una insistent menció al guaret (veióc;), i amb ell la necessitat d'enriquir els sòls grecs que eren molt pobres. En general intervé el concepte de deixar els animals sobre el camp que descansa. L'adob animal és un producte molt comú en l'agricultura grega (Alfaro 1995: 29).

17. Aquest fet està fonamentat amb la troballa, durant la fase Vilars II, de l'única eina de ferro vinculada a les tasques productives. Malgrat tot, durant la primera edat del ferro (fase Vilars 0) ja s'havia evidenciat el treball del ferro a partir de la troballa d'un forn de reducció situat en un espai de la zona 4 (barri sud).

18. A partir de les dades antracològiques, arqueobotàniques, l'anàlisi dels sòls i els resultats dels estudis pol-línics de Balasch
- Les zones de més altitud, situades al sud-est, és on podien concentrar-se boscos humits (alzina i roure) ideals per a l'alimentació de porcs i cabres durant les estacions de tardor, hivern i primavera. Les cabres també podrien alimentar-se en els erms i les zones més degradades i poc aptes per a l'agricultura.

- Pel que fa als recursos del bosc, cal destacar també que dels arbres i arbustos més aptes per ésser utilitzats com a farratges: l'ullastre, ${ }^{19}$ l'om, el freixe, el roure i l'alzina, a la fortalesa només van identificar-s'hi les dos últimes espècies. L'om, que seria l'aliment més adequat per al ramat boví, i l'ullastre, que té el potencial pecuari més elevat per a la cabana domèstica en general, no estarien presents a l'entorn de la fortalesa. L'aportació de fulles d'olivera ha estat una pràctica constant en les pràctiques ramaderes mediterrànies (Martínez

(2003), es va elaborar una primera aproximació de la distribució dels recursos agrícoles i vegetals del jaciment en una àrea d'uns $5 \mathrm{~km}$ al voltant.

19. La fulla de l'ullastre té un contingut en matèria grassa molt superior al dels altres arbres i al dels farratges clàssics, incloses les herbàcies (Boza et al. 1984). 

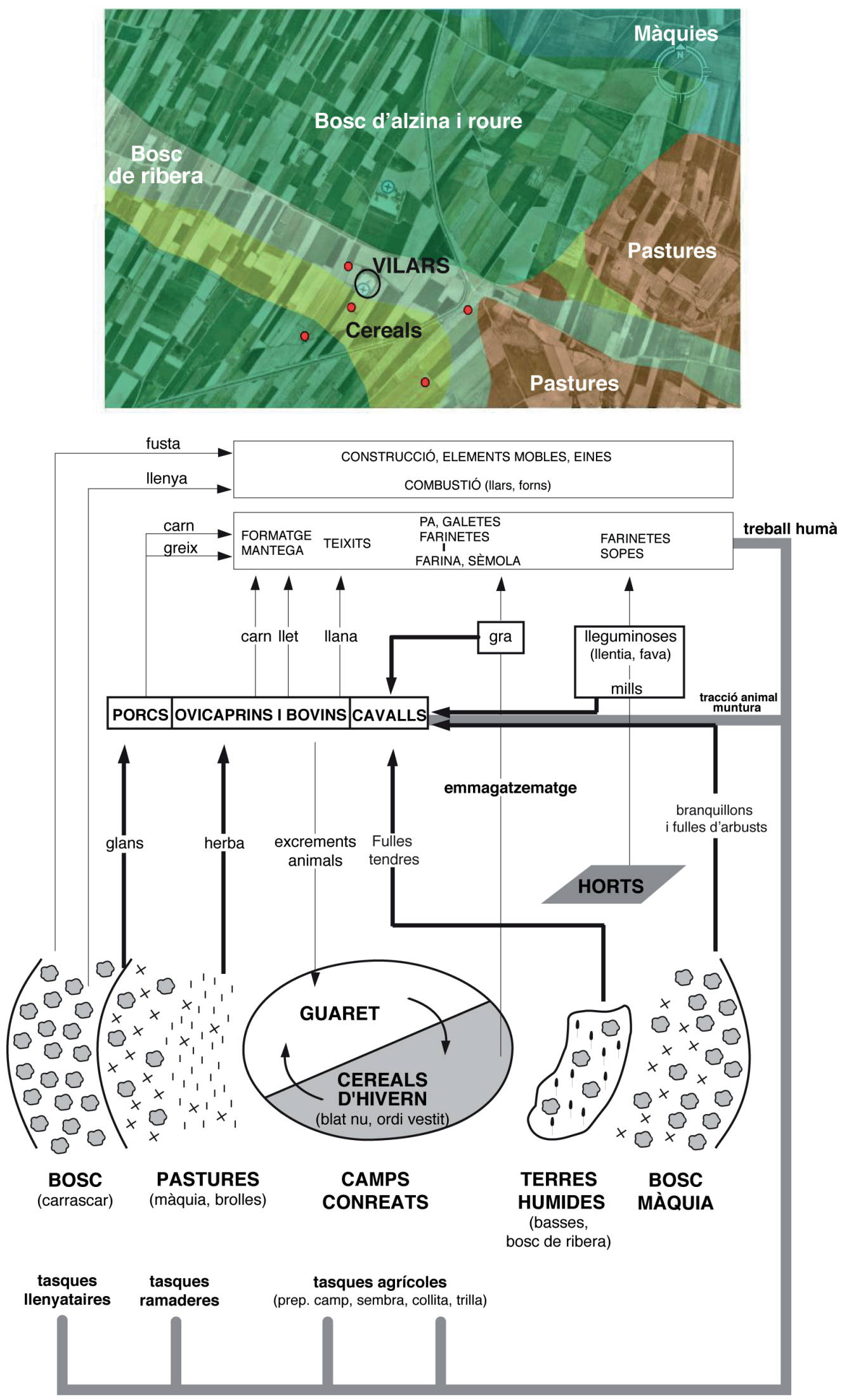

Figura 6. La part superior: distribució teòrica de les potencialitats dels sòls situats al voltant de la fortalesa, així com una reconstrucció teòrica de les zones d'explotació agrícola i de coberta vegetal (Figura elaborada pel GIP (Grup d'Investigació Prehistòrica) a partir d'un treball inèdit de Rosa $M^{a}$ Poch). A la part inferior: el model esquemàtic de Mazoyer i Roudart (1997, fig. 6.1) de l'organització i funcionament d'un ecosistema conreat en els sistemes de guaret i conreu amb arada lleugera, amb ramaderia associada. Aquest va ser ampliat $\mathrm{i}$ adaptat a les dades conegudes pel jaciment dels Vilars d'Arbeca (Alonso 1999) i en aquest treball també l'hem ampliat afegint alguns aspectes sobre l'alimentació animal. Les fletxes més gruixudes són les que fan referència als aliments disponibles per als animals domèstics. 
i Palanca 1991). A més a més, aquestes fulles són un millor substitut a la dieta d'herbàcies que l'alzina i el roure (que sí que s'han localitzat als alentorns del jaciment) (Badal 1999: 74).

- En les petites extensions prop de l'Aixaragall, en horts, hi podrien cultivar les lleguminoses, complements indispensables per a l'alimentació dels animals. Sobretot faves, que són les més nutritives, energètiques i recomanables per la majoria d'autors llatins, tal com hem vist en els apartats anteriors. A més, les zones de ribera, pel tipus de vegetació que hi ha, serien les més adequades per als bovins i ovins.

- Els estudis antracològics també han mostrat una discreta però progressiva antropització i obertura d'àrees al bosc. Aquestes pastures i la constatació de l'ús del guaret (Alonso 1999) permetrien una alimentació òptima per a ovelles, bovins i cavalls, almenys durant els mesos de primavera i tardor. Aquestes espècies necessiten una dieta rica en herba verda de qualitat. En aquest sentit, però, cal tenir en compte que hi ha diverses espècies que no poden pasturar en els mateixos espais, com ara els bovins i els cavalls. També haurien de disposar, doncs, de pastures per poder tenir a part les femelles gestants, que s'han de separar del grup i han de situar-se en les millors pastures. En canvi, ovelles i bovins sí que podrien conviure en les mateixes pastures perquè tenen uns costums que permeten que se socialitzin (Hafez i Dyer 1972: 134).

- Les terres planeres són molt aptes per al conreu de cereals (blat nu, ordi i mill). La constatació del conreu d'ordi i l'obtenció de subproductes de les collites com a farratge (Alonso 1999), deixen entreveure la possible voluntat d'obtenir els cereals més adequats per a l'alimentació de cada espècie. L'ordi és el més indicat per als cavalls. Tot i així, també s'hauria pogut destinar a la resta d'espècies domèstiques.

El mill, segons Columel.la, és el més aconsellable per als bovins, tot i que també recomana una bona dosi d'ordi quan aquests han acabat la jornada de treball. Les ovelles haurien de disposar de cereals i farratges d'alta qualitat, com l'ordi barrejat amb llegums. En canvi, l'ús de la palla no seria de gaire ajuda durant els mesos d'hivern i estiu, ja que la seva aportació energètica és pràcticament nul.la. Aquest subproducte agrícola normalment es destina més a l'entreteniment de l'animal que no pas a l'alimentació, de manera que si no es barreja amb cereals, llegums o farratges, no és una aportació energètica eficaç.

A partir de les aproximacions teòriques dutes a terme per Alonso (1999), la comunitat resident als Vilars, amb una població estimada d'uns 150 habitants, permet considerar les activitats productives de la següent manera: el conreu de blat podria ocupar unes 108 ha (amb un cicle biennal) al qual se sumarien unes 50 ha més per a l'ordi. Sempre comptant a la baixa, ja que l'autora suposa les condicions més favorables i una producció destinada a l'autoabastiment. Tanmateix, veient la versatilitat i els contrastos entre una espècie i una altra, cal tenir en compte algunes dades de les quals malauradament no disposem:
1. Els ovicàprids i els bovins necessiten un aportament diari de sals minerals ${ }^{20}$ (sal) ja que és fonamental per a una nutrició adequada. Un recurs bàsic en el cas d'haver de mantenir un gran nombre de caps de bestiar.

2. La quantitat de femelles, mascles i individus castrats (tenen un consum divers) de cada espècie.

3. La quantitat anual de femelles gestants (també necessiten una alimentació adaptada rica en complements energètics).

4. Saber si hi ha un o dos parts anuals en els ovicàprids.

5. Normalment les aproximacions a les necessitats nutricionals provenen de tractats d'època romana, medieval o contemporània, on els formats, la talla i el pes de cada espècie han variat moltíssim. Aquestes dades difícilment es correspondran a les necessitats que podrien tenir les races rústiques i de talles menors observades als Vilars.

Tot i les limitacions inherents a la recerca arqueològica esmentades anteriorment, el que sí permeten apuntar els resultats obtinguts és que els recursos naturals de l'entorn estaven molt diversificats i que sí que podrien suplir i respondre satisfactòriament les necessitats alimentàries de cada espècie.

\section{L'àmplia presència de fetus detectada es pot considerar l'evidència d'una ramaderia poc desenvolupada $i$ una alimentació deficient?}

La constatació d'un nombre molt elevat de fetus en totes les fases i pràcticament sectors (figura 7), ens ha alertat sobre la possible existència d'un alt percentatge d'avortaments i per tant de possibles deficiències en els processos reproductius dels animals. En primer lloc, si tenim en compte el moment en què s'haurien produït els avortaments en les diferents espècies de la tríada domèstica ${ }^{21}$ (figura 8), s'observen diferents tendències —el cas específic de l'avortament en èquids no es tractarà en aquest article ja que ha estat objecte d'un treball específic en anteriors publicacions (Nieto 2010; Nieto et al. 2010)—:

- Els ovicàprids tenien un patró d'avortaments molt homogeni ${ }^{22}$ i la major part s'haurien produït al llarg del quart mes de gestació (la forquilla va dels 2 als 3,7 mesos). Tenint en compte els tractats de

20. En el cas de Celtibèria s'ha constatat la presència de nombroses salines com a proveïdores d'un recurs imprescindible a l'hora de mantenir grans ramats (Vega et al. 1998: 124). Aquest podria ser un indicador de la talla reduïda dels ramats en el cas dels Vilars.

21. Aquests s'han establert a partir del calendari ramader de Columel.la i de les dades biomètriques (a partir de la longitud de la diàfisi dels diferents ossos llargs i l'escàpula), i les dades necessàries per a la identificació taxonòmica i anatòmica s'han extret dels treballs de Prummel (1987). Naturalment les dades són aproximatives, ja que som conscients que la variabilitat de talla de la col-lecció de referència de Prummel podria haver provocat algunes petites variacions. Però també hem tingut en compte la formació dels ossos i la presència, o no, dels centres d'ossificació, que ens permeten saber si els fetus estarien entre la primera o la segona fase de la gestació.

22. Aquesta estimació ha estat possible a partir de les dades biomètriques de 12 ossos llargs. 
Vilars I

\begin{tabular}{|c|c|c|c|}
\hline Sectors & NR fauna & NR fetus & $\%$ \\
\hline $4 / 1$ & 54 & 0 & 0,0 \\
$4 / 2$ & 93 & 2 & 2,2 \\
$4 / 3$ & 12 & 0 & 0,0 \\
$4 / 6$ & 4 & 0 & 0,0 \\
$4 / 7$ & 726 & 2 & 0,3 \\
$4 / 10$ & 218 & 15 & 6,9 \\
$4 / 17$ & 152 & 1 & 0,7 \\
$4 / ?$ & 149 & 1 & 0,7 \\
\hline $5 / 4$ & 15 & 0 & 0,0 \\
\hline $11 / 4$ & 11 & 1 & 9,1 \\
$11 / 9 \mathrm{~A}$ & 50 & 1 & 2,0 \\
$11 / 10$ & 3 & 0 & 0,0 \\
$11 / 14$ & 43 & 1 & 2,3 \\
$11 / 28 \mathrm{~A}$ & 25 & 0 & 0,0 \\
$11 / 28 \mathrm{~B}$ & 2 & 0 & 0,0 \\
$11 / 29$ & 24 & 0 & 0,0 \\
$11 / 29 \mathrm{~A}$ & 4 & 2 & 50,0 \\
$11 / 29 \mathrm{~B}$ & 44 & 8 & 18,2 \\
\hline Total & $\mathbf{1 6 2 9}$ & $\mathbf{3 4}$ & $\mathbf{2 , 1}$
\end{tabular}
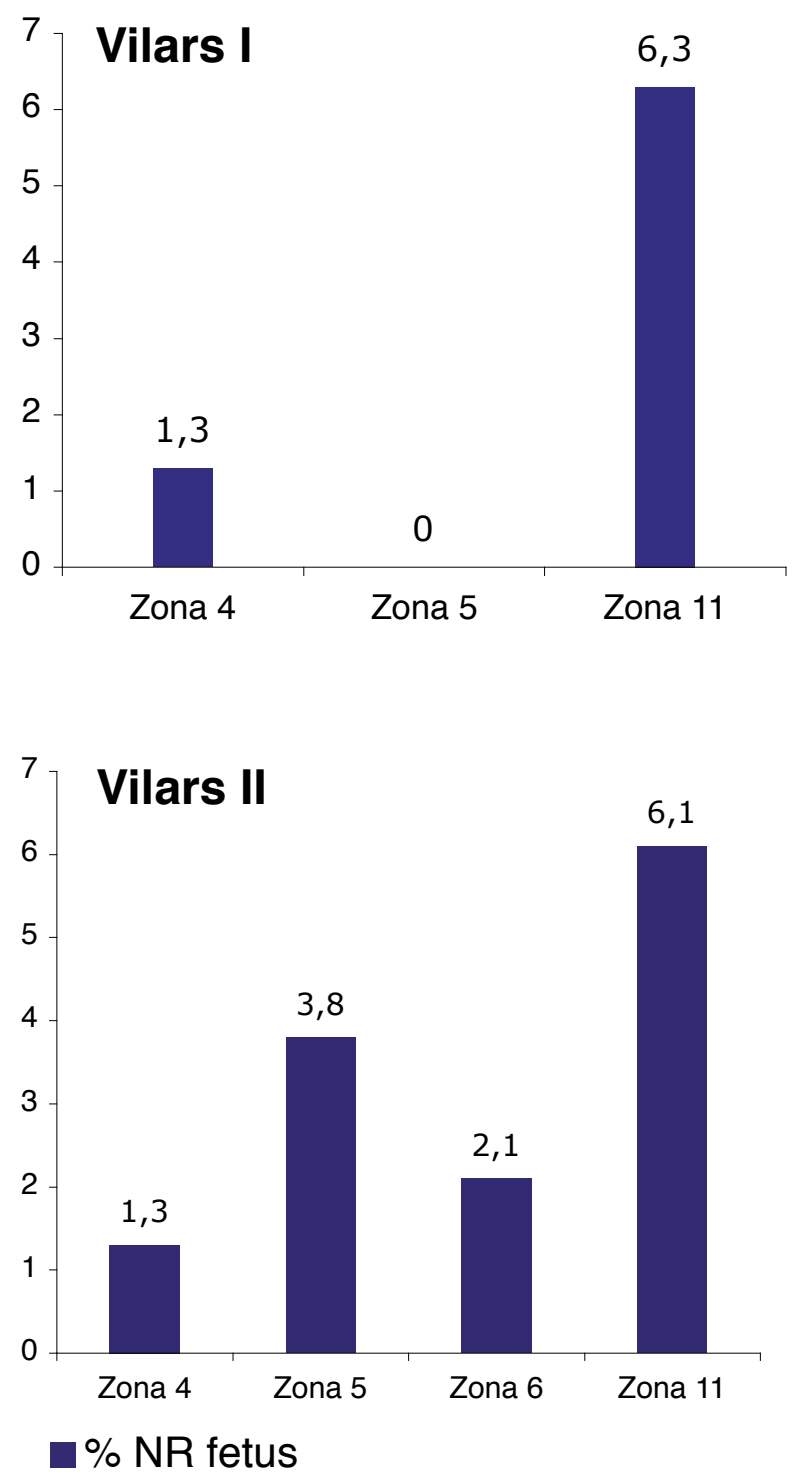

Vilars II

\begin{tabular}{|c|c|c|c|}
\hline sectors & NR Fauna & NR Fetus & $\%$ \\
\hline $4 / 4$ & 27 & 1 & 3,7 \\
\hline $4 / 5$ & 340 & 2 & 0,6 \\
\hline $4 / 8$ & 21 & 1 & 4,8 \\
\hline $4 / 9$ & 266 & 6 & 2,3 \\
\hline $4 / 18$ & 346 & 0 & 0,0 \\
\hline $4 / 24$ & 22 & 2 & 9,1 \\
\hline $4 / 25$ & 16 & 2 & 12,5 \\
\hline $5 / 1$ & 28 & 2 & 7,1 \\
\hline $5 / 2$ & 70 & 2 & 2,9 \\
\hline $5 / 3$ & 7 & 0 & 0,0 \\
\hline $6 / 3$ & 78 & 1 & 1,3 \\
\hline $6 / 4$ & 563 & 9 & 1,6 \\
\hline $6 / 5$ & 156 & 6 & 3,8 \\
\hline $6 / 6$ & 83 & 1 & 1,2 \\
\hline $6 / 7$ & 275 & 5 & 1,8 \\
\hline $6 / 9$ & 57 & 0 & 0,0 \\
\hline $6 / 10$ & 133 & 3 & 2,3 \\
\hline $6 / 12$ & 100 & 1 & 1,0 \\
\hline $6 / 13$ & 191 & 5 & 2,6 \\
\hline $6 / 17$ & 70 & 1 & 1,4 \\
\hline $6 / 18$ & 25 & 0 & 0,0 \\
\hline $6 / 20$ & 27 & 0 & 0,0 \\
\hline $6 / 21$ & 53 & 1 & 1,9 \\
\hline $6 / 22$ & 5 & 0 & 0,0 \\
\hline $6 / 23$ & 141 & 3 & 2,1 \\
\hline $6 / 32$ & 156 & 3 & 1,9 \\
\hline $6 / 33$ & 102 & 2 & 2,0 \\
\hline $6 / 34$ & 20 & 2 & 10,0 \\
\hline $6 / 38$ & 129 & 7 & 5,4 \\
\hline 6/39 & 136 & 1 & 0,7 \\
\hline $6 / 40$ & 13 & 2 & 15,4 \\
\hline $6 / 41$ & 29 & 0 & 0,0 \\
\hline $6 / 42$ & 26 & 0 & 0,0 \\
\hline $10 / 2$ & 89 & 0 & 0,0 \\
\hline $11 / 2 A$ & 242 & 22 & 9,1 \\
\hline $11 / 2 B$ & 0 & 0 & 0,0 \\
\hline $11 / 2 C$ & 73 & 1 & 1,4 \\
\hline $11 / 3 A$ & 67 & 2 & 3,0 \\
\hline $11 / 3 B$ & 251 & 16 & 6,4 \\
\hline $11 / 3 C$ & 80 & 3 & 3,8 \\
\hline 11/3D & 19 & 0 & 0,0 \\
\hline $11 / 4$ & 20 & 1 & 5,0 \\
\hline $11 / 5$ & 109 & 5 & 4,6 \\
\hline $11 / 6$ & 65 & 6 & 9,2 \\
\hline $11 / 7$ & 12 & 0 & 0,0 \\
\hline $11 / 10$ & 34 & 1 & 2,9 \\
\hline $11 / 11$ & 85 & 16 & 18,8 \\
\hline $11 / 12$ & 26 & 2 & 7,7 \\
\hline $11 / 13$ & 9 & 1 & 11,1 \\
\hline $11 / 24$ & 56 & 2 & 3,6 \\
\hline
\end{tabular}



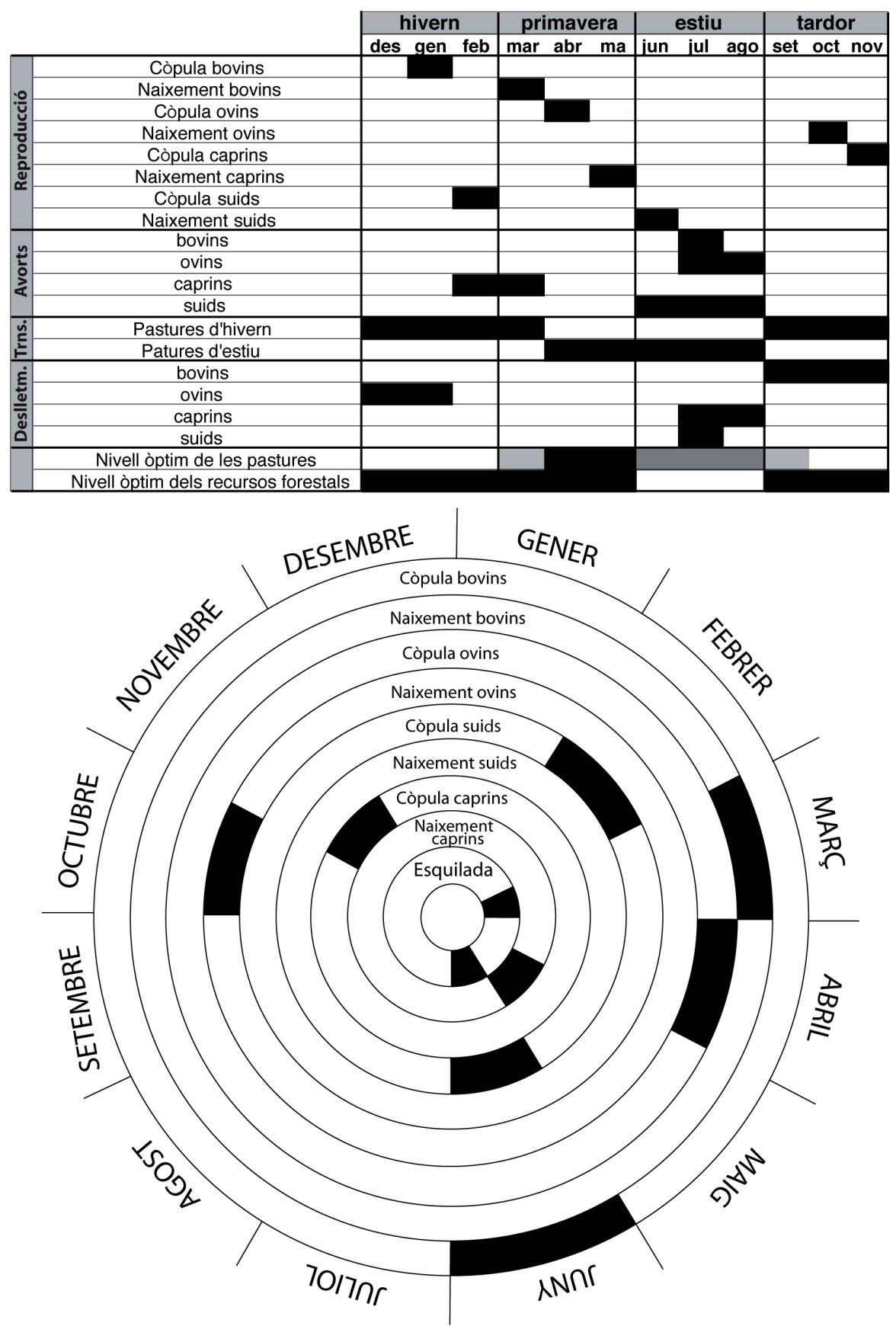

Figura 8. A la part superior: taula amb els mesos en els quals s'haurien produït la majoria dels avortaments de les diferents espècies de la tríada. La taula també proporciona informació sobre les potencialitats dels recursos vegetals, el clima i l'estacionalitat. A la part inferior: cicle anual ramader segons Columel.la a De re rustica, on s'especifiquen els mesos més adequats per al naixement i la còpula dels bovins, ovicaprins i suids.

Columel.la, en el cas de les ovelles, aquest moment coincidiria amb els mesos d'estiu quan les pastures es troben en un fort retrocés, el clima és més extrem i segurament hi ha menys disponibilitat d'aigua. Les mares estarien en els últims mesos de la gestació, una fase clau en què tenen les màximes necessitats energètiques. ${ }^{23}$ Això implicaria la necessitat d'una complementació important de

23. Les necessitats de les ovelles augmenten des del tercer mes de gestació i arriben al punt àlgid durant el període d'alletament (Drogoul et al. 2004). la dieta amb aportacions de cereals (ordi), farratges i, si podia ser, lleguminoses. Si, en canvi, es tractés de cabres, aquest moment coincidiria amb el final de l'hivern, que també és un moment en què les femelles estarien sortint d'uns mesos difícils amb alimentació de baixa qualitat i unes condicions climàtiques dures. De totes maneres, les cabres, com ja havíem comentat, s'haurien pogut alimentar del sotabosc i dels erms durant l'hivern i haurien pogut superar de manera molt més eficaç aquestes mancances alimentàries. 
- Per als bovins tenim molt poques dades, ${ }^{24}$ però les que tenim disponibles han mostrat uns avortaments situats durant els 5,5 mesos d'embaràs. Aquests coincideixen amb el mes de juliol i, per tant, durant els mesos en què les pastures podrien garantir només un $30 \%$ de l'alimentació d'aquests animals, i més si parlem de femelles gestants. Tanmateix, hi ha altres indicadors que podrien estar evidenciant que els habitants de la fortalesa serien eficients a l'hora de cuidar els animals joves durant l'hivern. Totes les fases presenten alts percentatges d'animals que han superat el seu primer hivern (Vilars $\mathrm{I}=85 \%$, Vilars II $=99$ \%, Vilars III=97 \%). Això és una constatació important, ja que la mortalitat natural en els bovins salvatges és molt elevada durant el seu primer hivern. Els vedells joves són molt sensibles a l'escassetat d'aliment, i els animals de dos i tres anys requereixen més farratges en augmentar d'edat (Higham i Message 1980: 334). Segons aquests autors, el fet que hi hagi una proporció tan gran d'animals que ha superat el primer i el segon any de vida suggereix no només que les comunitats serien hàbils en la cura dels vedells durant l'hivern, sinó també que disposarien d'un adequat farratge hivernal. ${ }^{25}$

- Els treballs de Prummel (1987) no oferien per als suids $^{26}$ un espectre de mesures que permetés fer estimacions d'aquest tipus. Malgrat això, a partir del grau de formació òssia i la comparació amb l'únic individu mesurat i dibuixat per Prummel (1987), vam veure que la majoria dels individus estarien molt poc formats i en el moment de l'avortament evidenciarien un estadi situat en la primera fase de gestació. Per tant, els avortaments se situarien durant els mesos d'estiu, que casualment són els únics mesos en què el seu principal recurs natural (els boscos) està en retrocés absolut. De manera que dependrien íntegrament de l'alimentació que els aportés l'home.

Amb això no pretenem atribuir tots els avortaments a una deficient alimentació dels ramats, sobretot tenint en compte que els processos abortius de cada espècie poden estar determinats per multiplicitat de factors com: epidèmies; infeccions; manca d'aigua; components genètics; cops a causa de la rivalitat entre femelles; canvis bruscs de la temperatura; situacions climàtiques extremes; avortaments provocats; sacrifici de les mares per al consum; etc. Per aquest motiu és difícil, amb les dades de què disposem, poder afirmar d'una manera rotunda que es produ-

24. Malgrat que s'han identificat diversos fetus d'aquesta espècie, només es va poder mesurar un metacarp, ja que la resta d'ossos no estaven suficientment complets per poder extreure'n aquestes dades.

25. Se sap amb certesa que durant el neolític suís es prestava una atenció considerable a la recol-lecció de farratges d'hivern en forma de fulles i plançons (Higham i Message 1980: 334). A partir de les enquestes a pagesos i agricultors de la plana occidental catalana, també destaquem la importància de la recol-lecció de farratges per l'hivern (parlen principalment de gramínies i trèvol que barrejaven puntualment amb la palla del cereal durant els mesos més durs de l'hivern) (fonts orals: Emili i Josep M. Espinet, 97 i 90 anys respectivament, Benavent de Segrià, Lleida) llargs.

26. Per a aquesta espècie disposàvem de 8 mesures d'ossos ïssin per una única causa, ja que podria tractar-se d'una confluència de factors. Tanmateix, sembla que coincideixin amb els moments en què els recursos naturals òptims per a cada espècie es troben en el seu màxim retrocés, és a dir, amb els períodes de l'any en què aquests animals serien més dependents de la comunitat humana i, per tant, dels excedents agrícoles que els poguessin oferir.

Aquestes dades, unides al fet que als Vilars només s'ha trobat un magall27 de ferro (segons Alonso 1999: 332) durant la fase Vilars II $\left(550 / 525\right.$ - 425/400 aC), ${ }^{28}$ $\mathrm{i}$ al fet que en realitat les primeres patologies de treball i/o tir no apareixen fins a la fase Vilars III en èquids i bovins (Nieto 2012), ens portaven a qüestionar la capacitat excedentària del jaciment $i$, per tant, la capacitat d'alimentar els animals amb subproductes agrícoles. Tampoc podem afirmar, en absolut, que això impliqui que durant les fases anteriors els bovins no es poguessin utilitzar per a les tasques agrícoles (amb el que això implica a nivell productiu), o que no coneguessin l'arada pel fet de no haver-la trobat físicament al jaciment. Ara bé, ens obliga a ser prudents en les conclusions.

Un element interessant són les dades indirectes que ens poden proporcionar les corbes d'edat de mort, que mostren un canvi de tendència clar al llarg dels diferents períodes. El més marcat el trobem durant el pas de l'edat del ferro a l'ibèric ple, moment en què s'observa una gestió més especialitzada i més encarada a l'obtenció i optimització dels recursos de la tríada. En general, la sensació és que hi ha un major manteniment dels animals en vida.

Però a què responen aquests canvis de tendència? En realitat podrien estar vinculats a factors socials, ideològics, mediambientals i/o econòmics. D'una banda, una major capacitat de manteniment dels animals en vida, i potser unes majors possibilitats de creixement dels ramats, ens podria suggerir una major productivitat agrícola $i$, per tant, una major quantitat de subproductes agrícoles destinats als animals. Ara bé, també podria estar reflectint un canvi en els gustos i/o preferències alimentàries, un canvi en les tècniques ramaderes fruit de la introducció de nous tipus de gestió, un canvi climàtic, etc.

Sigui el que sigui, el que està clar és que l'entrada a l'època ibèrica mostra canvis importants en tots els nivells, però a la vegada manté elements de continuïtat significatius respecte al període anterior. ${ }^{29}$ En definitiva, la fase Vilars II seria un moment de transició que encara suposaria una dependència important respecte a les possibilitats paleoecològiques de l'entorn. Aquest fet encaixaria perfectament amb els resultats carpològics que parlen d'una producció

27. Aquesta eina estaria vinculada al treball agrícola i de desforestació, de manera que el fil corbat cap amunt serviria per fer rodar els troncs (White 1975: 63 citat per Alonso 1999: 332).

28. Aquest moment coincideix amb una notòria davallada dels percentatges d'alzina i un augment del pi blanc i d'espècies de brolla, relacionades segurament amb una antropització del medi, que guanya espais al bosc (Alonso et al. 1998).

29. Encara hi ha el pic característic de sacrificis en les edats infantils d'ovicàprids i un consum preferentment carni dels bovins. També hi ha un alt percentatge de fetus i una renovació molt ràpida dels ramats. 
agrícola basada en l'autoabastiment i que estaria fortament condicionada per la irregularitat de les collites. Tot plegat provocaria una situació d'inseguretat i inestabilitat en l'aprovisionament de les comunitats con $^{30}$ (Alonso 1999: 468).

Desgraciadament disposem de poques dades per a les fases de l'ibèric ple (Vilars III), però les que tenim ja estan suggerint models de gestió ramadera que, com veurem més endavant, són pràcticament iguals als de la costa, ja sigui per una "globalització dels costums" (Albizuri et al. 2010), ja sigui per innovacions tecnològiques que van permetre a aquestes comunitats assegurar un excedent i, per tant, el manteniment $i$ creixement dels seus ramats.

\section{Cal plantejar-se la possibilitat de la pràctica de la transhumància durant la primera edat del ferro i l'època ibèrica? Quines evidències en tenim?}

La base de l'activitat ramadera és la recerca constant de pastures que, en definitiva, són la font principal d'aliment dels ramats. L'àmplia representativitat dels ovicàprids i la tradicional pràctica de la transhumància a la qual normalment poden anar associats, van incentivar alguns autors a posar-la en valor en el context ibèric de la plana occidental (Cura i Principal 1993). Però quines evidències tenim i quines novetats han aportat els estudis arqueofaunístics en aquest sentit?

\section{Les evidències de les fonts llatines}

Cura i Principal (1993) van recollir de les fonts llatines algunes citacions interessants que consideraven molt significatives a l'hora de reflectir aquesta activitat. La primera fou la de Corneli Escipió (l'Africà) que, per intentar atreure els rebels a una posició desfavorable per al combat, utilitzà un parany consistent a escampar ramats de bestiar per la zona. Sabia la importància que el bestiar tenia per als pobles indígenes, i per aquest motiu haurien corregut a controlar els animals. Les fonts també parlen de la necessitat de reprendre les hostilitats durant l'hivern; una dada curiosa quan tenim en compte que en l'antiguitat la guerra es feia principalment durant els mesos de primavera i estiu. Segons Cura i Principal aquest fet tindria una explicació versemblant si es tenen en compte els períodes transhumants, ja que durant l'estiu una part important de la població s'hauria desplaçat a les zones de les pastures d'alta muntanya per conduir els ramats. Això hauria provocat que els romans no haguessin trobat gaire resistència a les planes interiors durant aquests mesos. Finalment, una altra referència interessant és la de Polibi (3-76.3), que també va ser recollida per Titus Livi (21.60), i deia textualment "però el botí de la ciutat fou de poca vàlua: aixovar, bàrbars i vils esclaus", referint-se al botí obtingut en la presa de l'oppidum de Cissa $^{31}$ (després de la batalla del 218

30. Les xifres de rendiments de la plana occidental a l'edat mitjana i a l'època moderna presenten una important diferència en els rendiments de regadiu i secà (Bolòs 1993: 77; Serra 1988: 189).

31. És un oppidum contemporani al de Puig Castellar, potser inclús més important i amb un emplaçament exacte desconegut, però probablement situat cap a l'interior del Camp de Tarragona (Martínez i Vicente 1966: 13).
aC). De nou la interpretació de Cura i Principal és que en realitat si la riquesa fossin els recursos ramaders i no el gra, quan els romans haurien arribat al poblat durant l'estiu-primavera, la seva principal riquesa no hi seria, perquè estaria alimentant-se a les abundants pastures de muntanya.

Tot i això, no trobem cap referència explícita a aquesta activitat fins al segle $\mathrm{I} \mathrm{aC}$, ja en època romana i a partir dels textos de Varró. A més a més, molts autors fan referència a les rutes i camins transhumants documentats des de l'època medieval o moderna per justificar aquesta pràctica en èpoques prehistòriques. Aquests autors reflecteixen, doncs, una realitat social, política, territorial, cultural i econòmica molt diferent $\mathrm{i}$, per tant, difícilment extrapolable directament a l'època ibèrica o inclús anterior.

El desplaçament massiu de ramats a grans distàncies és sempre una font de conflictes importants, incentivada per la preservació dels camps agrícoles i les pastures reservades als propis ramats. ${ }^{32}$ A més a més, també comporta un desgast físic important dels animals, un conflicte amb els llauradors en travessar terres conreades o la mateixa zona d'hivernada i, fins i tot, la integració social en la comunitat receptora que no deixa de veure els pastors com a forans (Morales i Seguí, format digital: 6).

Tot plegat engendraria conflictes territorials i segrests de caps de bestiar, entre d'altres. Per tant, la pràctica transhumant a llarga distància necessita una estructura territorial unificada sota un mateix sistema polític i unes lleis estructurades que evitin conflictes de territorialitat entre comunitats. En definitiva, un sistema d'aliances i clienteles o una unificació territorial fruit d'una organització protoestatal. Aquest context seria absolutament necessari per garantir el pas dels grans ramats transhumants pels diferents territoris. Una realitat territorial que difícilment podem constatar durant la primera edat del ferro i l'ibèric antic a la plana occidental.

32. Una dada significativa sobre la incompatibilitat entre consum animal i recursos naturals de les comunitats queda ben exemplificada amb la preocupació expressada en alguns textos grecs. Els diversos santuaris que gestionaven una part important de terres i pastures de la zona de l'Arcàdia i del Peloponès, tenien lleis reguladores molt estrictes per a l'ús i benefici de la part d'aquest territori que arrendaven a particulars. Aquests reflecteixen, juntament amb la preocupació per controlar el consum de pastures del santuari, el desig d'evitar abusos dels ramats que estarien de pas en clara referència a la transhumància dins d'aquesta zona. També mostren una preocupació pel control del sòl, tal com mostra de vegades el reglament relatiu a la protecció del santuari dedicat a Apol-lo Liceu a Argos, on es prohibia fins i tot l'entrada a cavall al témenos (terreny consagrat al déu per evitar que els èquids es mengessin el que estava reservat al ramat productiu). El mateix cas, referit a diverses espècies de càrrega, l'ofereix un petit santuari de finals del segle IV i principis del III aC dedicat al culte a Alectrona a Iàlisos. Aquests animals estaven exclosos de l'accés a les pastures del territori proper al santuari (Alfaro 1995: 24). Referent també a aquest aspecte, trobem la intervenció de Javier Ibañez en el debat dut a terme al final del IV Simposio sobre los celtíberos: economía, que ja fa menció de la conflictivitat entre els pastors i agricultors. També parla de les represàlies que hi ha hagut en algunes ocasions en les zones de planura quan aquests ramats malbarataven els camps i tot plegat acabava amb el segrest d'animals, que no es tornaven si no era per intervenció real o perquè els pastors de la serra volien recuperar-los (Jiménez 1999: 159). 


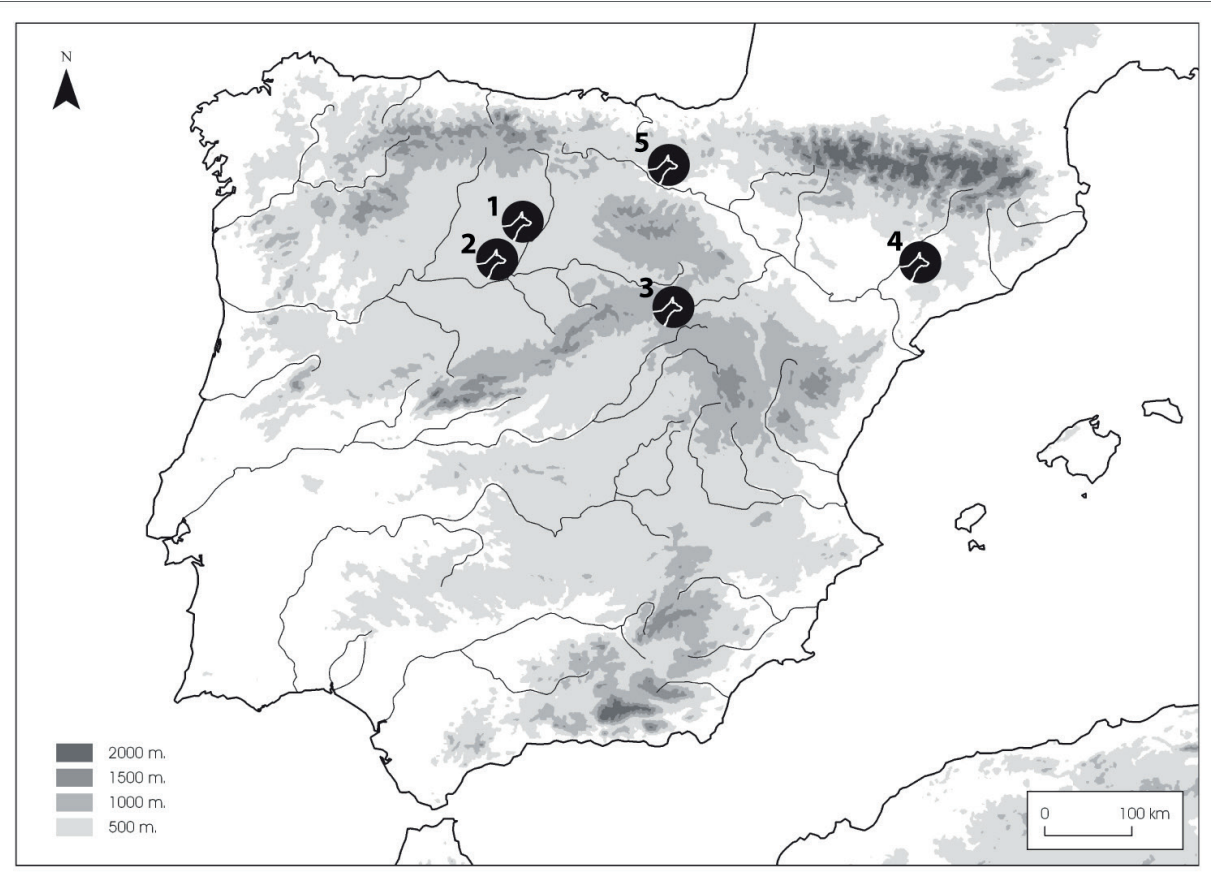

1. Cerro del Castillo (Montealegre de Campos, Valladolid)_Ferro I.

2. Soto de Medinilla (Valladolid)_s. III-II aC.

3. Castilmontán (Somaén, Soria)_s. I aC.

4. La fortalesa dels Vilars (Arbeca, Lleida)_s. IV aC (Ibèric ple).

5. La Hoya (Àlaba)_s. IV-II aC (fase celtibèrica).

\section{A. Copròlit de cànid (UE 7076). Aquest} es va localitzar al sector del baixador de la cisterna

B. Escàpula de cànid de talla (la de coloració més fosca) gran situat a la cisterna (UE 7078). Aquesta ha estat comparada amb dos gossos de talla mitjana i un de talla petita de la Col-lecció de comparació del laboratori d'arqueologia de la UdL.

C. Atles d'un cànid de talla gran (la de color més fosc de la part superior) que va sortir al baixador de la cisterna (UE 7076). També comparada amb dos mascles i una femella de talla mitjana de la col·lecció de referència.
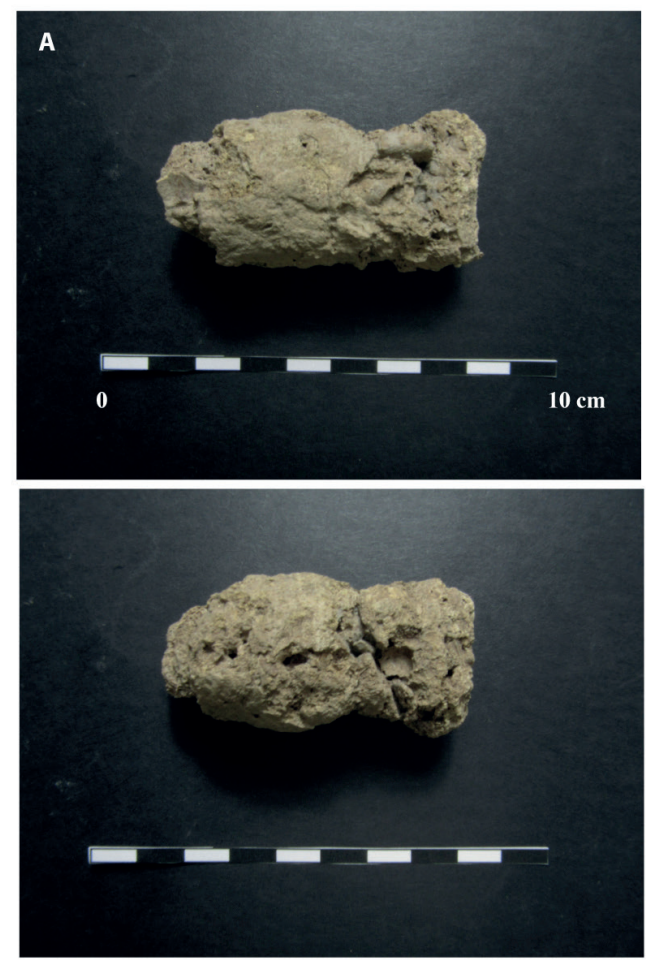
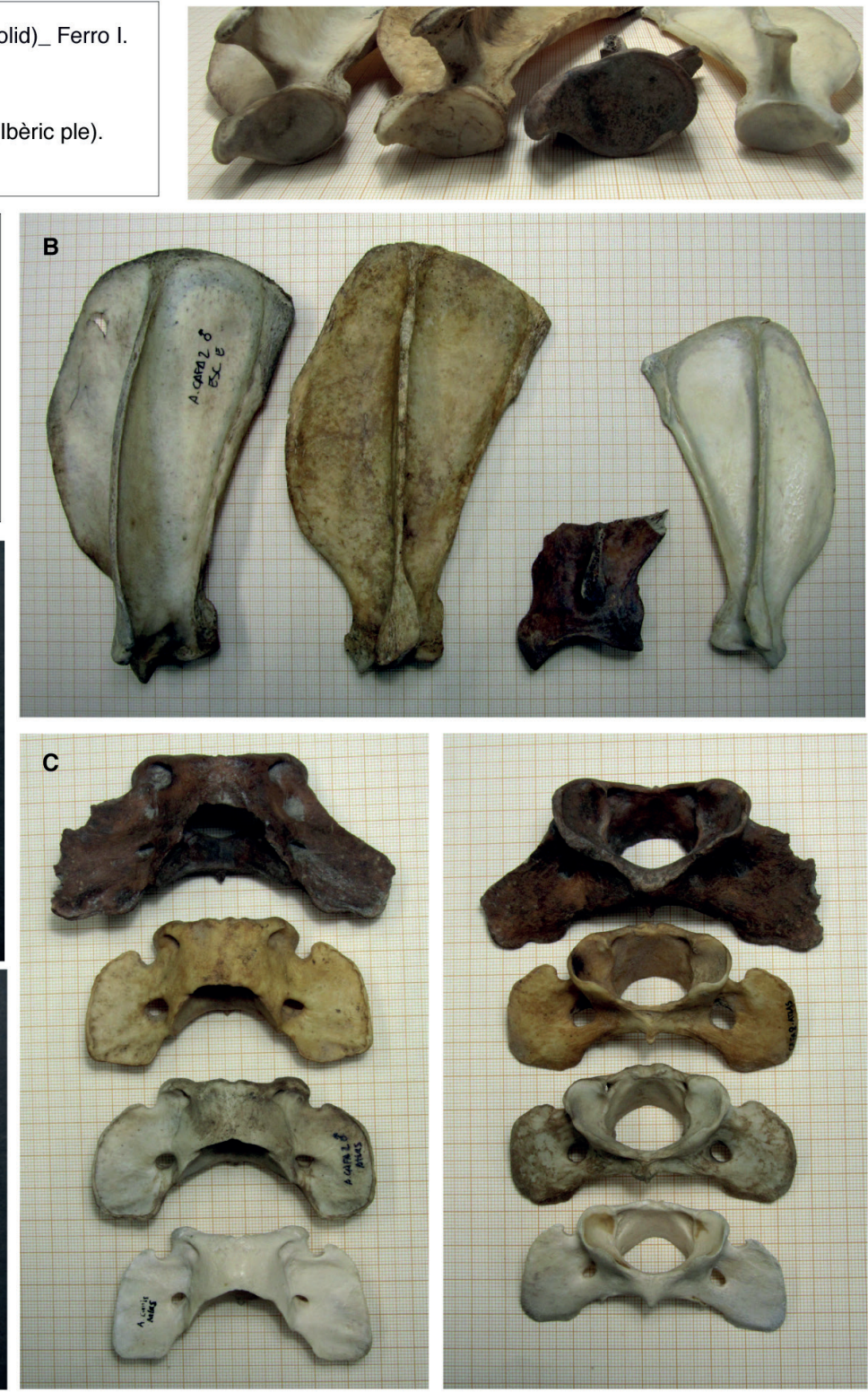

Figura 9a. A la part superior hi ha un mapa on apareixen representats els jaciments on han aparegut restes de cànid de talla gran. Les fotografies inferiors corresponen a les restes òssies d'un cànid de talla gran i un copròlit procedents de la cisterna de la fase Vilars III (ibèric ple). 


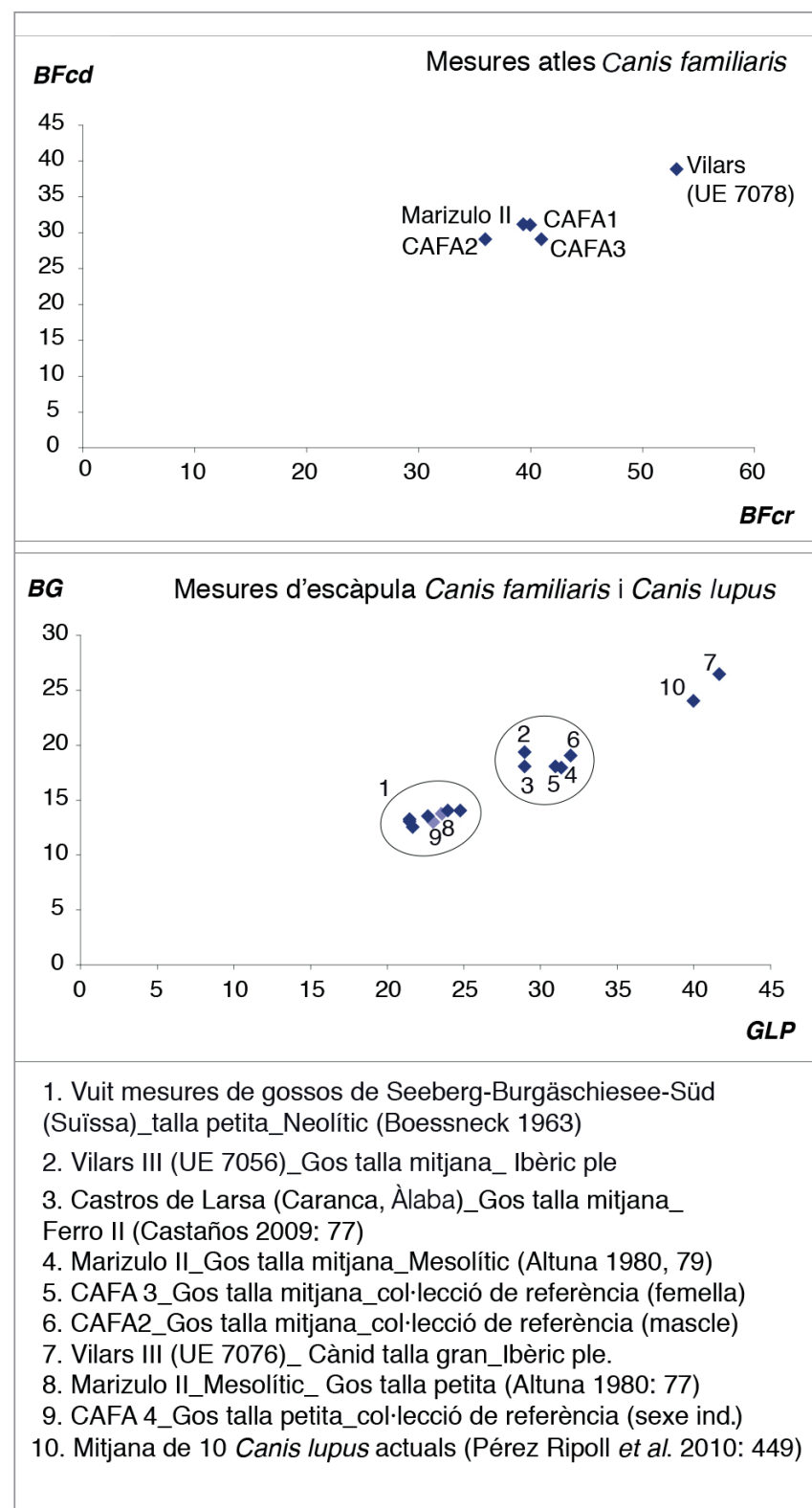

Figura 9b. Comparació biomètrica d'una escàpula i un atles de cànid dels Vilars amb les mesures d'altres exemplars de talles diverses extretes d'altres jaciments peninsulars.

\section{Les evidències arqueozoològiques}

Les restes arqueozoològiques poden aportar infinitat de dades per valorar si va existir, o no, la mobilitat dels ramats. Malauradament les més concloents són aquelles analítiques que no recauen en l'observació macroscòpica dels ossos. ${ }^{33}$ En aquest estudi ens hem centrat en tota la informació que puguem extreure de les dades directes que proporcionen els ossos (biometria i morfologia).

33. Actualment els mètodes més eficaços per estudiar l'aprofitament dels recursos vegetals són, d'una banda, l'estudi de la microtraceologia dentària, que permet veure si els animals han estat alimentant-se en zones de pastura ecològicament diferents. Però sobretot i principalment per les analítiques isotòpiques (estronci i oxigen), que detecten la mobilitat animal a partir de la composició d'isòtops estables dels aliments ingerits (p. e.: Walker 1983; Sánchez-Moreno 1998; Arnold i Greenfield 2006 Viner et al. 2010; Minniti et al. 2014; Valenzuela et al. 2015).
La transhumància sempre ha estat associada a la imatge de ramats i pastors realitzant desplaçaments en cerca de noves pastures, deixant en un segon pla un animal que realment és coprotagonista, al costat de l'home, en aquests llargs trajectes. Estem parlant del gos, ja que sense ell seria impensable poder realitzar aquests grans desplaçaments plens de perills, tant per als ramats com per als pastors. D'aquesta manera la presència/absència de gossos de gran talla tipus mastí s'ha apuntat com un indicador clau en els moviments a llarga distància.

Columel.la, en un apartat dels Dotze llibres de l'Agricultura, ja fa menció de les diferents tipologies canines en funció de la tasca que han de dur a terme: "el gos de guardar el bestiar, en estable o pastoreig, no ha de ser tan lleuger com els que persegueixen als gamons, ${ }^{34} \mathrm{o}$ als cérvols (...) però el suficient perquè pugui barallar-se contra els llops, i lleuger per seguir-los quan fugen, fer-los deixar la presa i tornar-la. El cos, per tant, serà gran i llarg. Per a tota la resta, semblant al de guarda, però variant el color. Han de ser de color clar, perquè es distingeixin de la fera durant la nit, quan es tracti de fer front als llops, de manera que no els puguem confondre. També perquè aquesta vegada si és clar no excitaran tant les ovelles en ser d'una tonalitat semblant a la seva".

Per altra banda, i a partir de les evidències arqueològiques, Altuna (1980) ja parla de dos tipus diferents de gos durant la primera edat del ferro a la península, almenys pel que fa a la seva talla. Un de menor que coincidirà amb el Canis familiaris intermedius i un altre de talla major que coincidiria amb el Canis familiaris inostranzewi o el Canis familiaris matris-optimae.

A la plana occidental no s'havia pogut constatar una variabilitat de talla durant la primera edat del ferro, on els gossos semblen presentar una talla mitjana i una morfologia molt homogènia hereva de les espècies del període del bronze. Aquestes característiques semblen adaptar-se, i fan aquestes espècies més aptes per a la caça que per a la guarda dels ramats.

Aquesta homogeneïtat sembla trencar-se en arribar al període de l'ibèric ple, on sembla que la fortalesa dels Vilars ha lliurat les dos primeres restes de cànid d'una talla anormalment gran (figura 9a). Totes van aparèixer en el mateix context cronològic dins la cisterna.

No tenim coneixement de cap altra troballa d'aquestes característiques a Catalunya, almenys en aquest context. Ara bé, en altres punts de la península sí que s'han documentat, de manera molt puntual i escadussera, algunes restes i/o evidències arqueològiques de cànids de talla anormalment gran. Alguns d'ells van ser recollits en un treball sobre l'origen dels mastins ibèrics i la seva relació amb l'activitat transhumant (Vega et al. 1998). La zona més prolífica va ser la de la Meseta (figura 9a), on s'han localitzat un fragment

34. Es refereix als gossos de caça amb unes característiques morfològiques ben diferenciades respecte als gossos de guarda. En aquest cas serien gossos més aviat de talla mitjana, lleugers i ràpids per poder perseguir millor les preses. 
de coxal a Soto de Medinilla (Escudero 1995: 187), un atles a Castilmontan (Arlegui 1990: 54) i diversos copròlits a Cerro del Castillo (Morales i Liesau 1995: 473). Més al nord, el jaciment de la Hoya (Altuna 1980: 79) també va proporcionar un extrem distal d'húmer, dos ulnes i un extrem distal de tíbia de gossos de talla gran. Tot i que les cronologies van de la primera edat del ferro fins a l'època celtibèrica, són races que no tindrien res a veure amb la introducció de nous agrotips durant l'època romana.

Si comparem les dades biomètriques dels exemplars de Vilars (atles i escàpula) amb les d'alguns jaciments de la Meseta i/o celtibèrics de diferents cronologies i amb la mitjana de les mesures de l'escàpula de 14 Canis lupus actuals procedents de l'Estació Biològica de Doñana i del Museu Nacional de Ciències Naturals (Pérez Ripoll 2010: 449) podem observar que tot i que a la fortalesa també hi ha els gossos de talla mitjana, les restes trobades a la cisterna presenten una talla anormalment gran (figura 9b) que s'aproximen a la talla dels llops actuals.

Un dels principals criteris distintius que s'ha utilitzat per separar el gos del seu agrotip salvatge, Canis lupus, sempre havia estat principalment la talla. En tot cas considerem que aquest no pot ser un criteri diagnòstic per si sol, ja que cal tenir en compte tant l'estudi de la morfologia de l'animal així com el context d'aparició de les restes. En aquest sentit i a l'espera d'obtenir els resultats de les analítiques d'ADN, ${ }^{35}$ l'única afirmació possible és la de l'existència d'almenys un cànid de talla gran durant el segle IV $\mathrm{aC}$ a la fortalesa. Però pot evidenciar aquesta presència una activitat transhumant $i$ una relació amb les zones de la Meseta o amb la zona celtibera? Pot estar mostrant una major importància de l'activitat ramadera i un creixement dels ramats que necessitaria l'ajuda i protecció d'uns gossos de major talla en els desplaçaments cap a les zones de pastura llunyanes?

Tot i que en la zona de la Meseta s'ha relacionat l'aparició d'aquests anomenats "mastins" amb un canvi clar en l'estratègia ramadera, ${ }^{36}$ el jaciment dels Vilars, en canvi, no presentaria uns canvis tan marcats com els descrits en els jaciments de la Meseta. L'entrada al període ibèric sí que reflecteix un canvi progressiu, que potencia més els productes en vida de l'animal. Però això no vol dir que hi hagi una especialització ramadera centrada en els ovicàprids o en una gestió orientada vers els productes secundaris. La presència d'aquests gossos podria respondre a qüestions principalment socials o de prestigi, sense negar un ús més funcional vinculat al manteniment i protecció del bestiar. En definitiva, amb un registre tan limitat i la composició i gestió que es fa dels ramats, en aquest cas no considerem que aquest tipus de restes puguin estar relacionats amb una activitat transhumant, tot $\mathrm{i}$

35. Aquestes analítiques formen part d'un projecte més ampli en relació amb l'estudi genètic sobre la variabilitat de Canis lupus a la península Ibèrica sota la direcció d'Òscar Ramírez de l'Institut de Biologia Evolutiva (CSIC-Universitat Pompeu Fabra): <http://www.ibe.upf-csic.es/>.

36. Passa a especialitzar-se en la cria dels ovicàprids, i d'una explotació càrnia a una explotació dels productes derivats (llana i llet) (Vega et al. 1998: 124). que sí que pensem que la presència de diferents talles de gos al jaciment pot mostrar una diversificació en els usos d'aquesta espècie, fruit d'una nova realitat socioeconòmica a la plana.

\section{Les evidències històriques i arqueològiques}

A part de les restes faunístiques, altres elements que podrien reflectir l'activitat pastoral són les tisores d'esquilar. Ni als Vilars ni a cap altre jaciment de la plana s'ha trobat evidències d'aquests objectes durant la protohistòria recent, però aquesta realitat podria respondre a la constant amortització, refosa i aprofitament dels recursos metàl-lics que sembla haver-hi a la fortalesa durant la primera edat del ferro i època ibèrica.

Una altra dada sobre l'obtenció i manufactura de la llana l'han proporcionat les corbes d'edat de mort, que no semblen evidenciar una gestió orientada cap a l'obtenció d'aquest producte. Tot i que no hi hauria una explotació que possibilités un excedent important per a l'intercanvi, sí que permetria, però, un consum propi que també estaria documentat a partir de la presència de fusaioles i de pesos de telar, que són les que evidencien el processat i filat de la llana in situ. La taula no mostra una gran quantitat de pondus (en total 5 per a totes les fases), tot i que les fusaioles sí que són més nombroses.

Un altre punt a destacar és que la presència de materials i sistemes constructius comuns s'han interpretat per alguns autors com a fruit de contactes periòdics amb comunitats d'altres regions; uns contactes que vindrien motivats precisament per l'activitat transhumant (p. e.: Vega et al. 1998). A la Meseta, a Extremadura i a la Celtibèria, per exemple, el tipus de poblament eren petits enclavaments rodejats de muralla, a l'interior dels quals hi havia habitatges adossats de planta rectangular, prova d'un hàbitat estable que sens dubte explotava els recursos agrícoles necessaris per sostenir una ramaderia mòbil que tenia els seus centres permanents en aquests enclavaments. A més, aquests jaciments tenen en comú unes defenses desproporcionades i interpretades com a dissuasives davant de possibles atacs durant l'absència periòdica d'una part dels seus habitants. Un model molt similar es documenta a la Meseta occidental i a Galícia, encara que amb diferències en la forma dels habitatges i un tret comú molt característic com és la presència del sistema defensiu de pedres clavades (chevauxde-frise). Aquestes defenses estan documentades en vàries regions peninsulars (figura 10), tot i que són més nombroses en els castros sorians de l'orient de la Meseta (Romero 2003), en els de la Meseta occidental (Esparza 2003), en els de l'interior de Galícia i a Tras Os Montes a Portugal (Redentor 2003), i se'n coneix només un exemple a la Celtibèria (Guijosa, Guadalajara) i tres a la Betúria cèltica (Capote a Higuera Real, Passo Alto a Beja i Pic del Castillo a Huelva) (Berrocal-Rangel 2003). Finalment per a la zona de Catalunya només s'ha pogut documentar el de la fortalesa dels Vilars durant la primera edat del ferro (GIP 2003: 233-274). Segons Vega et al. (1993), l'escassa presència d'aquestes defenses a les zones del 
sud de la península així com a l'àrea catalana es pot considerar com un "préstec" de les poblacions que freqüentment visitaven aquests llocs i, en definitiva, com un element que pot demostrat aquesta mobilitat dels ramats. Alguns autors inclús parlen d'un "corredor longitudinal" vall de l'Ebre-Extremadura/Alemtejo per explicar la presència al sud-oest de tipus ceràmics en principi originaris de cercles del nord-est (p. e.: Berrocal 1994: 258).

L'explicació d'aquests elements comuns fruit dels contactes a partir de la mobilitat pastoral, no la considerem sostenible a partir de les dades disponibles, ja que no hi ha proves empíriques i directes que ens permetin atribuir aquests elements comuns fruit de la pràctica transhumant. Jesús Arenas ja adverteix que "cuando se superaron las tesis invasionistas, todo tenía que ser indigenista, todo tenían que ser procesos endógenos, y entonces utilizamos un comodín que fue la transhumancia, es decir, estuvieses donde estuvieses, encontrabas unos objetos, unos elementos que te remitían a contextos tremendamente lejanos y lo único que podía explicar eso era la transhumancia" (Jiménez 1999: 159). Per tant, els contactes i l'adopció de nous sistemes defensius que clarament tindrien l'origen en el món celta, no han d'implicar també una mobilitat dels ramats a grans distàncies sinó més aviat una mobilitat de coneixements, persones, tècniques i objectes.

\section{Les evidències etnogràfiques i la diversificació del concepte}

Sobretot a partir dels estudis etnogràfics actuals en diverses zones de la Mediterrània s'ha pogut aprofundir en la varietat de tipologies de moviments relacionats amb el tipus de gestió tradicional del ramat. Aquest fet qüestiona, sens dubte, la generalització de l'ús de la paraula transhumància en el marc dels estudis arqueològics. Tal com adverteixen Morales i Seguí (digital): "per entendre aquesta forma de gestió ramadera cal contraposar-la a l'espectre ample del pastoralisme com a forma econòmica". A partir dels diversos treballs etnogràfics duts a terme a la zona valenciana, ambdós autors han pogut arribar a definir fins a 3 tipus diferents de mobilitat dels ramats en funció del tipus de gestió, les distàncies recorregudes i el context mediambiental.

- Desplaçaments transhumants: ${ }^{37}$ responen a la idea generalitzada de moviments de llarg recorregut que connecten territoris localitzats a llarga distància (impliquen alguns dies de recorregut) amb disponibilitat de pastures complementàries des del punt de vista ecològic (pastura d'hivern i d'estiu). N'hi ha nombrosos exemples al Mediterrani, alguns força esmentats com ara els desplaçaments auspiciats per la Meseta castellana o per la Dognana italiana. El que principalment distingeix la transhumància de la transterminància és el desplaçament de grans quantitats de bestiar, sobretot llaner. Una altra dife-

37. Aquests moviments solen anar associats a un nombre elevat de caps de bestiar i en definitiva responen a una major demanda alimentària que faria inviable una coexistència entre la producció agrícola i les demandes ramaderes.

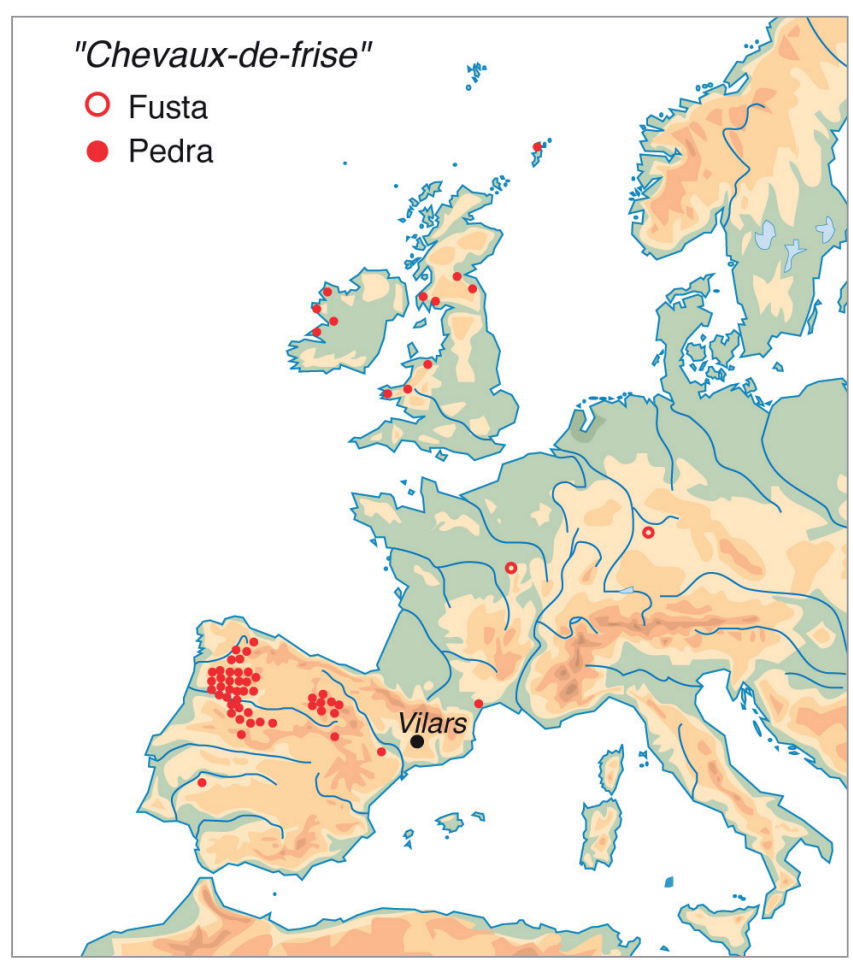

Figura 10. Distribució i localització dels jaciments amb presència de camps frisis (figura elaborada per GIP: Grup d'Investigació Prehistòrica, Universitat de Lleida).

rència seria que la primera suposa unes condicions socioeconòmiques complexes: necessitat d'un gran nombre de pastors, seguretat durant el recorregut i una ramaderia orientada vers l'obtenció de llana i no de carn. Per aquest motiu s'ha dit que aquest tipus de pràctica no hauria aparegut fins a època romana i no abans, com a conseqüència de la fragmentació ètnica del territori durant l'època protohistòrica (per a més detall sobre aquest aspecte, vegeu el punt de les fonts clàssiques).

- Desplaçaments transtermitants: sensu stricto "transtermitar" (transterminar) implica el traspàs de les fronteres administratives d'una localitat. Quan s'han definit els moviments transtermitants s'ha fet referència a desplaçaments de ramat entre territoris de poblacions veïnes $i$, per tant, el recorregut sol ser curt i en sentit vertical. Però, i més important si cal, els desplaçaments transtermitants, a diferència dels transhumants, no impliquen l'accés a zones de pastura ecològicament diferents, impliquen simplement l'accés a major quantitat de pastures. Moviments d'aquest tipus estan ja documentats al període medieval a la zona mediterrània peninsular (Fernández 1996). Existeixen moltes modalitats socioeconòmiques que es poden adaptar a aquest tipus de mobilitat ramadera, però majoritàriament és practicada per societats camperoles en què la ramaderia juga un paper important i de les quals es podria inclús trobar exemples prehistòrics peninsulars. ${ }^{38}$

38. S'han detectat desplaçaments estivals de petits ramats d'ovicàprids des de les zones baixes del sud-est d'Espanya fins a la serra de Segura (Vega Toscano 1993). 


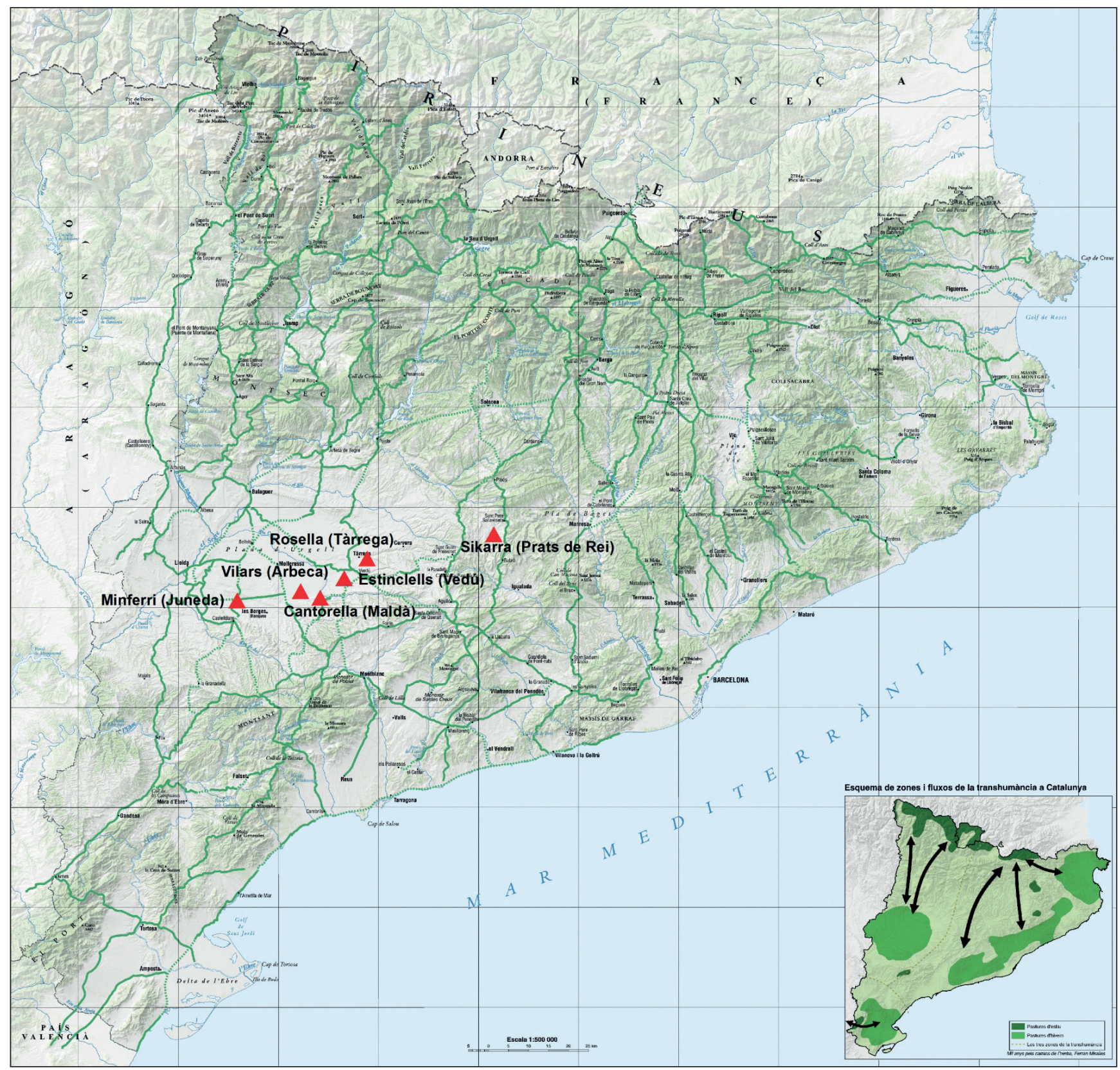

Figura 11. Mapa de camins ramaders de Catalunya (elaborat per la Fundació del Món Rural i Institut Cartogràfic de Catalunya) on s'ha situat la fortalesa dels Vilars juntament amb altres jaciments de la zona que actualment es troben en curs d'estudi.

- Desplaçaments locals: ${ }^{39}$ respon a una gestió estrictament "local" del ramat; és a dir, les àrees de pastura explotades són les disponibles en les rodalies de la població. Es tracta probablement del tipus de gestió més generalitzat al Mediterrani i acostuma a implicar un important grau de simbiosi amb els espais conreats. Aquest tipus de desplaçament podria correspondre amb l'anomenat ramaderia estant, que està definida per un tipus d'explotació camperola. Seria un complement de l'agricultura dominant i es caracteritzaria per un ampli espectre d'espècies, però per un reduït nombre de caps de bestiar. Aquesta modalitat no

39. Aquest està obligat a limitar la talla dels ramats a la producció agrícola i a la disponibilitat de pastures, normalment són de talla força reduïda o mitjana en funció de les possibilitats. demana desplaçaments ja que els animals poden alimentar-se dels subproductes vegetals.

Gràcies a estudis d'aquest tipus, s'ha constatat que les formes més corrents de gestió del ramat al Mediterrani en general són aquelles que permeten mantenir els animals dins d'un territori proper a la comunitat d'origen. Aquest tipus de moviments contenen, a més, una informació addicional al voltant de les estratègies de gestió que articulen, de manera quasi "íntima", agricultura i ramaderia a l'àmbit mediterrani. Pel perfil paisatgístic, climàtic i agrícola que s'ha descrit detalladament al punt anterior, sembla que la mobilitat dels ramats als Vilars podria adequar-se o bé amb el model de transterminància, o bé amb el de desplaçament local o ramaderia estant.

Una altra dada que permet acotar més sobre aquest aspecte, són els estudis etnogràfics de Halstead (1996) sobre les estratègies de grups ramaders actuals. 
Els diferents graus d'especialització que defineix ens permetrien descartar, a partir de la composició dels ramats, l'existència d'una comunitat de pastors especialitzats o de pastors poc especialitzats, amb el que això implicaria quant a la mobilitat. Si seguim els models de l'autor, cap fase estudiada no ha detectat una estratègia centrada i/o especialitzada en una sola espècie, tal com passa amb els pastors especialitzats, on el sistema requereix molts caps de bestiar per ser viable. Els grups humans que la practiquen han de ser nòmades o seminòmades. Tant aquest model com el dels pastors menys especialitzats depenen de la venda dels productes derivats, com la llana, la llet, els xais, els teixits i les manufactures. Tanmateix, tot i que aquesta pràctica s'ha pogut contrastar als Vilars principalment en entrar a l'ibèric ple, no serien els elements que haurien determinat la gestió dels ramats.

A partir de les dades que ens han proporcionat els estudis etnogràfics, sembla que la pràctica de la transhumància no s'hauria dut a terme en la zona estudiada. Tot i que no podem deixar de mencionar la situació estratègica de la fortalesa respecte a alguns dels camins ramaders/transhumants trandicionals (figura 11), tot apunta que la reduïda talla dels ramats hauria afavorit una ramaderia estant que s'hauria adaptat a les possibilitats que li oferien les zones de pastura propera, tot i que no podem descartar tampoc la pràctica de la transterminància. En aquest sentit, els primers estudis sobre mobilitat estacional d'ovelles a Catalunya partir de les analítiques d'estronci i oxigen (Valenzuela et al. 2015) sustentarien les nostres hipòtesis, posant de manifest que durant la primera edat del ferro els ramats del jaciment de Turó Font de la Canya (Penedès) no haurien recorregut grans distàncies, sinó que haurien practicat amb tota seguretat desplaçaments locals pel seu territori.

\section{Conclusions}

Els camins de la transhumància són rutes d'un passat que semblen desdibuixar-se en la distància. Una pràctica mil-lenària que constitueix una qüestió major pel que fa a la definició de models d'apropiació de l'espai i la construcció d'identitats. Per tant, el seu estudi també suposa entendre el context ecològic i social que va motivar i permetre aquesta pràctica (petits grups familiars, cabdillatges o protoestats). La transhumància només es dóna quan: 1) Hi ha escassetat de pastures a una època de l'any; 2) Hi ha acords que permeten el pas dels ramats per certs camins; 3) No hi ha cap estructura política ni social que impedeixi el pas dels ramats. Els futurs estudis han de tenir una clara vocació interdisciplinària i sobretot han d'explorar totes aquelles possibilitats que ofereixen les analítiques i els indicadors tant directes (analítques químiques) com indirectes (arqueologia, arqueobotànica, arqueozoologia, etnografia, fonts). D'aquesta manera, tot i que aquest treball s'ha centrat en la informació que ens proporcionen els indicadors indirectes, i no ens ha permès provar l'existència de la pràctica transhumant a la plana occidental catalana, sí que ha estat l'oportunitat de situar aquesta problemàtica a casa nostra, identificar les limitacions existents i organitzar el futur i els objectius de la recerca en aquesta línia.

D'aquesta manera el full de ruta a seguir s'ha de centrar, d'entrada, a ampliar l'espectre d'estudis arqueozoològics a la zona de la plana occidental, actualment molt poc nombrosos. Sens dubte els rics conjunts que han proporcionat jaciments com Minferri (Juneda), la Cantorella (Margalef), Molí d’Espígol (Tornabous), Sikarra (Prats del Rei) i la Rosella (Tàrrega) suposen un substrat excepcional de dades que deixa a disposició una informació tant a nivell diacrònic com territorial. L'estudi de les restes de fauna d'aquests jaciments permetrà veure si hi han canvis en les espècies criades i/o la mida dels animals al llarg del temps. D'altra banda, aquestes dades s'hauran de complementar amb analítiques isotòpiques d'oxigen i estronci, que són les que permeten detectar de manera directa la mobilitat. L'estronci varia segons la formació geològica i s'incorpora a l'organisme a través de l'aigua i els aliments. Per tant és el que permet determinar l'origen geogràfic de persones i animals. Pel que fa a l'oxigen, varia segons la temperatura ambiental. En latituds com Catalunya, on la temperatura varia significativament segons l'estació de l'any, les ràtios dels isòtops d'oxigen presents a l'esmalt dibuixen un patró que permet determinar l'estació de l'any. En aquest sentit, la zona de la plana occidental catalana ofereix un bon marc geogràfic per abordar aquesta qüestió perquè té una geologia ben diferenciada de la de les possibles zones d'estiuada dels ramats (zones pirinenques) i, al mateix temps, té una marcada variació estacional de la temperatura. La plana occidental s'erigeix, doncs, com una zona clau per a l'estudi de la mobilitat animal, per la potencialitat de materials i riquesa disponibles que sens dubte permetrà complementar les informacions exposades en aquest article i determinar amb seguretat l'existència o no d'aquesta pràctica a Catalunya.

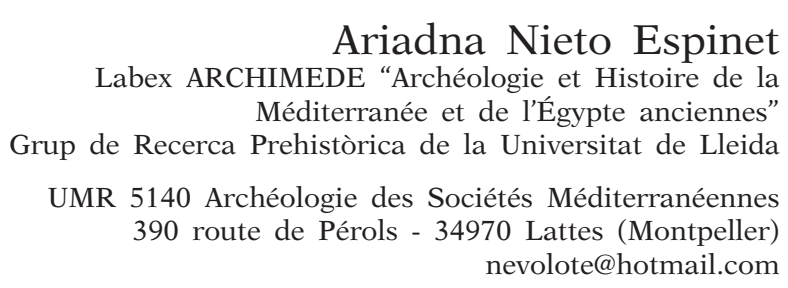

Rebut: 24-01-2016 Acceptat: $31-03-2016$ 
Albizuri, S., Nieto, A., Valenzuela, S. (2010). Canvis en l'alimentació càrnia a Catalunya entre els segles XII i III aC. Saguntum, Extra-9. Universitat de València: 161-170.

Alfaro, C. (1995). Las polis y la explotación ganadera en los santuarios griegos. POLIS, Revista de ideas y formas políticas en la Antigüedad Clásica, 7: 5-37.

Alonso, N. (1999). De la llavor a la farina: els processos agrícoles protohistòrics a Catalunya Occidental. Monographies d'Archéologie Méditerranéenne. UMR 5140. Lattes (Montpeller, França).

Alonso, N., Junyent, E., Lafuente, A. i López, J. B. (1998). Poder, símbolo y territorio: el caso de la fortaleza de Arbeca. Actas del Congreso Internacional: Los Iberos. Príncipes de Occidente. Barcelona: 355-372.

Altuna, J. (1980). Historia de la domesticación animal en el País Vasco desde sus origenes hasta la romanización. Munibe fasc. 1-2. Sant Sebastià: 147 p.

Arlegui, M. (1990). Introducción al estudio de los grupos celtibéricos del Alto Jalón. A: Argente, J. L. (coord.). El Jalón vía de comunicación. Soria: 41-70.

Arnold, E., Greenfield, H. (2006). The Origins of Transhuman Pastoralism in Temperate South Eastern Europe: A Zooarchaeological Perspective from the Central Balkans. BAR International Series 1538: 212 p.

BADAL, E. (1999). El potencial pecuario de la vegetación mediterránea: las Cuevas Redil. II Congrés del Neolític a la Península Ibèrica. Saguntum-Plav, Extra-2: 69-75.

Balasch, J. C. (2003). Reconstrucció paleoambiental de l'assentament iber d'Els Vilars (Arbeca, Les Garrigues): hidrografia, hidrologia i edafologia. Informe inèdit. Departament d'Història. Universitat de Lleida.

Berrocal, L. (1994). Oppida y castros en la Beturia Céltica. Castros y oppida en Extremadura. A: Almagro, M., Martín, A. M. (eds.). Complutum, extra 4: 189-241.

Berrocal-Rangel, L. (2003). La expansión meridional de los chevaux-de-frise: Los castros célticos del Suroeste. A: Alonso, N., Junyent, E., Lafuente, A., López, J. B. (coord.). Chevaux-de-frise $i$ fortificació en la primera edat del ferro europea. Universitat de Lleida: 209-232.

Blaise, E. (2005). L'élevage au Néolithique final dans le sud-est de la France: éléments de réflexion sur la gestion des troupeaux. Anthropozoologica , 40(1): 191-216.

Boessneck, J. (1963). Seeberg Burgäschisee Süd, Teil 3, Die tierreste. Acta Bernensia, II (Bern).

Bolòs, J. (1993). Paisatge i societat al Segrià al segle XIII. A: DDAA. Paisatge $i$ societat a la Plana de Lleida a l'Edat Mitjana. Espai/Temps. Universitat de Lleida: 46-81.
Boserup, E. (1967). Las condiciones del desarrollo en la agricultura. Tecnos.

Boza, J., Fonollá, J., Aguilera, J., Sanz, R., Molina, E., Guerrero, J., Escadon, J., Prieto, C., Muñoz, F. (1984). Subproductos de Andalucía. Aprovechamiento por distintas especies. A: Gómez et al. (eds.). Nuevas fuentes de alimentos para la produccion animal, II. Servicio de Publicaciones de la Universidad de Córdoba.

Castaños, P., Castaños, J. (2009). Estudio de la fauna de los Castros de Lastra (Caranca, Alava). KOBIE (Serie Paleoantropología), XXVIII: 51-88.

Coop, I. E., Devendra, C. (1982). Systems, biological and economic efficiencies. World Animal Science, C1: Sheep and goat production. Elsevier. Amsterdam: 297-307.

Cura, M., Principal, J. (1993). El Molí d’Espígol (Tornabous): Noves constatacions arqueològiques i noves propostes interpretatives entorn del món preromà. Laietania, 8: 63-83.

Driesch, A. (1992). Lélevage des animaux domestiques dans les cultures européennes pré- et protohistoriques. Revue de Médecine Vétérinaire, 143 (2): 113-137.

Drogoul, C., Gadoud, R., Joseph, M ${ }^{\mathrm{a}}$. M., Jussiau, R., Lisberney, M. J., Mangeol, B., Montméas, L., Tarrit, A. (2004). Nutrition et alimentation des animaux d'élevage. Tome 2. Editions Educagri. Djon.

Escudero, Z. (1995). Nuevos estudios sobre el poblado vecceo de "Soto de Medinilla" (Valladolid). A: Delibes, G., Romero, F., Moles, A. (eds.). Arqueología y Medio ambiente. El primer milenio a.C. en el Duero medio. Junta de Castilla y León. Valladolid: 179-218.

Esparza, E. (2003). Castros con piedras hincadas del oeste de la Meseta y sus aledaños. A: Alonso, N., Junyent, E., Lafuente, A., López, J. B. (coord.). Chevaux-de-frise $i$ fortificació en la primera edat del ferro europea. Universitat de Lleida: 155-178.

FERnández, C. (1996). La ganadería y la caza desde la Edad del Hierro hasta los inicios de la Edad Media en el noroeste. Férvedes, 3: 201-216.

GIP: Alonso, N., Colet, A., Gené, M., Gómez, X., Junyent, E., Lafuente, A., López, J. B., Moya, A., Tartera, A., Vidal, A. (2003). Caballos y hierro. El campo frisio y la fortaleza de "Els Vilars d'Arbeca" (Lleida, España), siglos viII-IV a.n.e. A: Alonso, N., Junyent, E., Lafuente, A., López, J. B. (coord.). Chevaux-de-frise i fortificació en la primera edat del ferro europea. Universitat de Lleida: 233-274.

Hadjikoumis, A. (2010). Traditional pig husbandry in southwest Iberia: results, discussion and conclusions. The origins and evolution of pig domestication in prehistoric Spain. Tesi doctoral. Departament of Archaeology. University of Sheffield: 381 p. 
Hafez, E., Dyer, I. (1972). Desarrollo y nutrición animal. Ed. Acribia. Saragossa.

Halstead, P. (1996). Pastoralism or household herding? Problems of scale ans specialization in early Greek animal husbandry. World Archaeology, 28, 1: 20-42.

Helmer, D., Vigne J. D. (2004). La gestion des cheptels de caprinés au Néolitique dans le midi de la France. Approches fonctionnelles en Préhistoire, $X X V^{e}$ Congrès Préhistorique de France. Nanterre: 397-407.

Higham, C., Message, M. (1980). Evaluación de una tecnica prehistórica de ganadería bovina. A: BROTHWELL, D., Higgs, E., Clark, G. (comp.). Ciencia en arqueología. Fondo de Cultura Económica de México.

IBORRA, M ${ }^{\mathrm{a}}$. P. (2004). La ganadería y la caza desde el bronze final hasta el ibérico final en el territorio valenciano. Serie de Trabajos Varios 103. Servició de Investigación Prehistórica. Diputación Provincial de Valencia.

Jiménez, A. (1999). Debate segunda ponencia y comunicaciones. A: Bruillo, F. (coord.). IV Simposio sobre celtíberos. Economía. Institución "Fernando El Católico”. Saragossa: 157-160.

Martínez, F., Palanca, F. (1991). Utillatge agrícola en ramaderia. Temes d'etnografia Valenciana (II). Ed. Alfons el Magnànim, IVEI: 300.

Martínez, A., Vicente, J. (1966). El poblat ibèric de Puig Castellar, excavacions dels anys 1954-1958. Institut d'Estudis Catalans. Memòries de la Secció HistòricoArqueològica XXIV. Barcelona.

MAzOyer, M., RoudART, L. (1997). Histoire des agricultures du monde, Le Seuil. París: 534 p.

Minniti Minniti, C., Valenzuela-Lamas, S., Evans, J., Albarella, U. (2014). Widening the market. Strontium isotope analysis on cattle teeth from Owslebury (Hampshire, UK) highlights changes in livestock supply between the Iron age and the Roman period. Journal of Archaeological Science, 42: 305-314.

Miró, J. M. (1992). Macrofauna. A: Garcés, I., Junyent, E., Lafuente, A., López, J-B. Dinàmica Paleoceològica $i$ Paleoeconòmica en l'assentament de "Els Vilars" (Arbeca, les Garrigues), Informe Projecte de Recerca, Secció d'Arqueologia Prehistòria i Història Antiga, Universitat de Lleida. Inèdit.

Morales, J. V., Seguí, J. (document digital). Introducció a un estudi etnoarqueolòic de l'activitat transhumant al nord del País Valencià. RDEC (Recerca i Difusió de l'Etnologia Catalana, Departament de Cultura i Mitjans de comunicació): <http://cultura.gencat.net/ cpcptc/ridec/>.

Morales, A., Liseau, C. (1995). Análisis comparado de las faunas arqueológicas en el valle medio del Duero (Valladolid) durante la Edad del Hierro. A: Delibes, G.,
Romero, F., Moles, A. (eds.). Arqueología y Medio ambiente. El primer milenio a.C. en el Duero medio. Junta de Castilla y León. Valladolid: 455-514.

Nieto, A. (2010). El caballo símbolo de poder. Investigación y Ciencia, 400: 6-7.

Nieto, A. (2012). Entre el consum i l'afecte. La interacció entre els animals $i$ les comunitats protohistòriques de la plana occidental catalana (segles VII - IV aC). tesi doctoral. Departament d'Història. Universitat de Lleida.

Nieto, A. (2013). Porcs, cavalls, ovelles i infants. Noves aportacions a les pràctiques rituals de la fortalesa dels Vilars (Arbeca, les Garrigues). Revista d'Arqueologia de Ponent, 23: 127-162.

Nieto, A., Gardeisen, A., López, J. B., Junyent, E. (2010). Inhumations de foetus d'équides dans la fortresse du premier âge du Fer de Els Vilars (Arbeca, Catalogne). A: Gardeisen, A., Furet, E., Boulbes, N. (eds.). Histoire d'équidés des textes, des images et des os. Monographies d'Archéologie Méditerraneenne. Hors-série 4: 126-147.

Pérez Ripoll, M., Morales, J. V., Sanchis, A., Aura, J. E., SARrión, I. (2010). Presence of the genus Cuon in upper Pleistocene and initial Holocene sites of the Iberian Peninsula: new remains identified in archaeological contexts of the Mediterranean region. Journal of Archaeological Science, 37: 437-450.

Prummel, W. (1987). Atlas for identification of foetal skeletal elements of Cattle, Horse, Sheep and Pig. Part 1. Archaeozoologia, 1: 23-30.

Prummel, W. (1987). Atlas for identification of foetal skeletal elements of Cattle, Horse, Sheep and Pig. Part 2. Archaeozoologia, 2: 11-41.

REDDING, R. W. (1981). Decision Making in Subsistence Herding of Sheep and Goats in Middle East. Ann Arbor. Michigan.

RedDing, R. W. (1984). Theorical determinants of a Herder's decisions: Modeling Variation in the Sheep/ Goat ratio. A: Clutton-Brock i Grigson, C. (eds.). Animals and Archeology, Early Herders and their Flocks. BAR International Series 202: 223-241.

Redentor, A. (2003). Pedras fincadas em Trás-os-Montes (Portugal). A: Alonso, N., Junyent, E., Lafuente, A., López, J. B. (coord.). Chevaux-de-frise $i$ fortificació en la primera edat del ferro europea. Universitat de Lleida: 135-153.

Romero, F. (2003). Piedras hincadas en el oriente meseteño. A: Alonso, N., Junyent, E., Lafuente, A., López, J. B. (coord.). Chevaux-de-frise $i$ fortificació en la primera edat del ferro europea. Universitat de Lleida: 179-208.

Ros, $M^{\mathrm{a}}$. T. (1992). Antracologia. A: Garcés, I.; JunYent, E.; Lafuente, A. i LóPez, J. B. Dinàmica paleoecològica $i$ paleoeconòmica en l'assentament dels Vilars (Arbeca, les Garrigues). Informe Projecte de Recerca inèdit, 
Secció d'Arqueologia, Prehistòria i Història Antiga, Universitat de Lleida: 51-60.

SÁNCHEZ-Moreno, E. (1998). Livestock, movement and contact. Reviewing the question of Transhumance in Hispanic Protohistory: the Western Meseta. Studia Historica, 16: 53-84.

Serra, E. (1988). Pagesos i Senyors a Catalunya del $s$. XVII. Baronia de Sentmenat 1590-1729. Crítica.

Sidi MaAmar, H. (2000). Approche archéozoologique de la diversité du "mode de production" pastoral au Premier Âge du Fer. Essai de caractérisation du "bestiaire de la table" villageois et princier. Mailhac et le Premier Âge du Fer en Europe occidental, Hommages à Odette et Jean Tafanel, Actes du Colloque International de Carcassone. Monographies d'Archéologie Méditerranéenne, 7: 215-228.

Sierra Alfranca, I. (1996). Sistemas de producción ovina. A: BuXADÉ (coord.) Zootecnia. Bases de producción animal. T. VIII. Madrid: 93-110.

Stein, G. J. (1987). Regional Economic Integration in Early State Societies: Third Millenium B.C. Patoral Production at Gritille, Southeast Turkey. Paléorient, Vol. 13, 2: 101-111.

SteIn, G. J. (2000). Material Culture and Social Identity: The Evidence for a 4th millenium BC Mesopotamian Uruk Colony at Hacienbi, Turkey. Paléorient, 25/1: 11-22.
Valenzuela-Lamas, S., Jiménez-Manchón, S., Evans, J., López, D., Jornet, R., Albarella, U. (2015). Analysis of seasonal mobility of sheep in Iron Age Catalonia (north-eastern Spain) based on strontium and ozygen isotope analysis from tooth enamel: First results. Journal of Archeological Science (en premsa).

Vega Toscano, L. G. (1993). Excavaciones en el Abrigo Molino de Vadico (Yeste). El final del Paleolítico y los inicios del Neolítico en la Sierra Alta de Segura. Arqueología en Albacete. Junta de Comunidades de Castilla-La Mancha. Madrid: 17-32.

Vega, L. G., Cerdeño, Ma . L., Córdoba, B. (1998). El origen de los mastines ibéricos. La transhumancia entre los pueblos prerromanos de la meseta. Complutum, 9: 117-135.

Viner, S., Evans, J., Albarella, U., Parker Pearson, M. (2010). Cattle mobility in pre-historic Britain: strontium isotope analysis of cattle teeth from Durrington Walls (Wiltshire, Britain). Journal of Archaeologycal Science, 37: 2812-2820.

WaLKer, M. J. (1983). Laying a Mega-Myth: Dolmens and Drovers in Prehistoric Spain. World Archaeology, 15 (1): 37-50.

White, K. D. (1975). Farm equipment of the Roman World. Londres. 